\title{
Teneurin-4 Is a Novel Regulator of Oligodendrocyte Differentiation and Myelination of Small-Diameter Axons in the CNS
}

\author{
Nobuharu Suzuki, ${ }^{1,2}$ Masaya Fukushi, ${ }^{1}$ Keisuke Kosaki, ${ }^{1}$ Andrew D. Doyle, ${ }^{1}$ Susana de Vega, ${ }^{1,3}$ Keigo Yoshizaki, ${ }^{1}$ \\ Chihiro Akazawa, ${ }^{2}$ Eri Arikawa-Hirasawa, ${ }^{3}$ and Yoshihiko Yamada ${ }^{1}$ \\ ${ }^{1}$ The Laboratory of Cell and Developmental Biology, National Institute of Dental and Craniofacial Research, National Institutes of Health, Bethesda, \\ Maryland 20814, ${ }^{2}$ Department of Biochemistry and Biophysics, Graduate School of Health Care Sciences, Tokyo Medical and Dental University, Tokyo \\ 113-8510, Japan, and ${ }^{3}$ Research Institute for Diseases of Old Age and Department of Neurology, Faculty of Medicine, Juntendo University, Tokyo 113-8421, \\ Japan
}

Myelination is essential for proper functioning of the CNS. In this study, we have identified a mouse mutation, designated furue, which causes tremors and hypomyelination in the CNS, particularly in the spinal cord, but not in the sciatic nerve of the PNS. In the spinal cord of the furue mice, myelination of small-diameter axons was dramatically reduced, and differentiation of oligodendrocytes, the myelinforming cells in the CNS, was inhibited. We subsequently found that the furue mutation was associated with a transgene insertion into the teneurin-4 (Ten-4, Ten-m4/0dz4) gene, encoding a transmembrane protein of unknown function. Ten- 4 was strongly expressed in the spinal cord of wild-type mice and was induced during normal oligodendrocyte differentiation. In contrast, in the furue mice, the expression of Ten-4 was absent. Differentiation and cellular process formation of oligodendrocytes were inhibited in primary cell culture from the furue mice. Cell differentiation and process formation were also inhibited in the oligodendrocyte progenitor cell line CG-4 after suppression of Ten-4 expression by shRNA. Furthermore, Ten-4 positively regulated focal adhesion kinase, an essential signaling molecule for oligodendrocyte process formation and myelination of small-diameter axons. These findings suggest that Ten-4 is a novel regulator of oligodendrocyte differentiation and that it plays a critical role in the myelination of small-diameter axons in the CNS.

\section{Introduction}

Oligodendrocytes are myelin-forming cells in the CNS. In mouse embryos, oligodendrocyte progenitor cells (OPCs) are produced from neuroepithelial stem cells in the ventral region of the neuroepithelium during spinal cord development. The OPCs cells subsequently proliferate and migrate throughout the entire spinal cord (Baumann and Pham-Dinh, 2001). In the early postnatal stages, OPCs begin to differentiate into oligodendrocytes in the white matter. During differentiation, oligodendrocytes form long and well-branched cellular processes and initiate expression

\footnotetext{
Received April 24, 2011; revised June 25, 2012; accepted July 2, 2012.
}

Author contributions: N.S., E.A.-H., and Y.Y. designed research; N.S., M.F., K.K., S.d.V., and K.Y. performed research; N.S. contributed unpublished reagents/analytic tools; N.S., M.F., A.D.D., C.A., E.A.-H., and Y.Y. analyzed data; N.S. and Y.Y. wrote the paper.

This work was supported by grants from the Intramural Program of the National Institute of Dental and Craniofacial Research and the National Institutes of Health (Y.Y.). N.S. was supported in part by the Research Fellowship of the Japan Society for the Promotion of Science for Young Scientists and the Grant-in-Aid for Young Scientists 23790979. We thank Andrew Cho and Ashok B. Kulkarni for creating the transgenic mouse lines, Franca Cambi and Tadashi Yamamoto for providing the CG-4 cell line, and Kenneth M. Yamada for providing the FAK constructs. We also thank Tadahiro Numakawa, Naoki Adachi, and Makoto Horiuchi for their help for the primary culture, Kang Feng and Reinhard Fassler for their help during the initial stage of the work, and Hynda K. Kleinman and Matthew P. Hoffman for their suggestions.

Correspondence should be addressed to Yoshihiko Yamada, The Laboratory of Cell and Developmental Biology, National Institute of Dental and Craniofacial Research, National Institutes of Health, 30 Convent Drive, Bethesda, MD 20814.E-mail:yyamada@dir.nidcr.nih.gov.

DOI:10.1523/JNEUROSCI.2045-11.2012

Copyright $\odot 2012$ the authors $\quad 0270-6474 / 12 / 3211586-14 \$ 15.00 / 0$ of myelin proteins, including myelin basic protein (MBP), proteolipid protein (PLP), and myelin-associated glycoprotein (Louis et al., 1992). Subsequently, the tips of oligodendrocyte processes contact surfaces of axons, and myelin sheaths are formed along axon fibers (Baumann and Pham-Dinh, 2001). Because myelin is necessary to accomplish proper body movements, severe defects in myelination result in impairments of normal body movements, such as tremors (Griffiths, 1996). Therefore, oligodendrocyte differentiation, including the proper expression of myelin proteins and cell process formation, is critical for the achievement of proper functioning of the CNS.

In addition to myelin proteins, intracellular signaling molecules are also involved in the differentiation of oligodendrocytes and CNS myelination. Focal adhesion kinase (FAK) has been identified recently as a key molecule for oligodendrocyte process formation and myelination. During differentiation of the OPC line CG-4, FAK is phosphorylated and is required for process outgrowth through the activation of the Rho family GTPases, Cdc42 and Rac1 (Hoshina et al., 2007). Oligodendrocyte-specific ablation of FAK causes hypomyelination of small-diameter axons in mice (Câmara et al., 2009; Forrest et al., 2009). Reduced FAK activation and defects in myelination of small-diameter axons are also seen after inhibition of signaling by integrin $\beta 1$, a transmembrane protein that binds extracellular matrix proteins and recruits and activates various intracellular proteins, such as FAK (Câmara et al., 2009). 
Teneurin-4 (Ten-4, Ten-m4/Odz4, hereafter referred to as Ten-4) is a type II transmembrane protein that is highly expressed in the CNS. Ten-4 is also expressed in developing eyes and somites, as well as in tail bud and limbs (Tucker and ChiquetEhrismann, 2006; Kenzelmann-Broz et al., 2010). Ten-4 expression is induced in response to endoplasmic reticulum stress (Wang et al., 1998), and an involvement of Ten-4 has been suggested in mouse gastrulation (Lossie et al., 2005) and bipolar disorder in humans (Sklar et al., 2011). However, the biological function of Ten-4 remains unknown.

In the present study, we identify a mouse mutation, designated furue, which results in tremors and severe hypomyelination of small-diameter axons and reduces oligodendrocyte differentiation, especially in the spinal cord of the CNS. These phenotypes are associated with the absence of Ten- 4 expression caused by a transgene insertion. Using the OPC line CG-4 and primary oligodendrocyte cultures, we demonstrate an important role for Ten-4 in oligodendrocyte differentiation and process formation and find that FAK is activated downstream of Ten- 4 both in vivo and in vitro. Our results indicate that Ten-4 is a new regulator for differentiation of oligodendrocytes and plays a critical role in CNS myelination.

\section{Materials and Methods}

Generation of mutant mice. The full length of perlecan cDNA with a FLAG tag at the $5^{\prime}$ end was cloned into the chondrocyte-specific Col2al promoter and enhancer expression construct pKN185 (p3108FC) (Noonan et al., 1991). pKN185 contains the Col2al promoter $(-956$ to +77$)$, the rabbit $\beta$-globin splice site, the SV40 polyadenylation signal, and the fragment of the Col2al first intron enhancer $(+2038$ to +2678$)$, which directs the expression of a foreign gene specifically in cartilage (Tsumaki et al., 1999). The plasmid p3108FC was digested with NotI to release the inserts from their vector sequences. Transgenic mice were produced by microinjecting each of the inserts into the pronuclei of fertilized eggs from C57BL/6 mice. The transgenic mouse line Perl ${ }^{+/ \mathrm{tg}}$ was maintained by crossing with C57BL/6 mice. For experiments, mice of either sex were used. All experimental procedures were approved by the Animal Care and Use Committee of the National Institute of Dental and Craniofacial Research.

$R T$-PCR. Total RNA was prepared from tissues or cells using TRI reagent (Sigma-Aldrich). After $1 \mu \mathrm{g}$ of total RNA digestion with DNase I (Sigma-Aldrich), the RNA samples were used for the RT using SuperScript III Reverse Transcriptase (Invitrogen) and Oligo dT Primer (Invitrogen). For the semiquantitative RT-PCR of mouse Ten-4 (nearly the entire coding sequence), cDNA was amplified with 30 PCR cycles at $98^{\circ} \mathrm{C}$ for $10 \mathrm{~s}$ and $68^{\circ} \mathrm{C}$ for $10 \mathrm{~min}$ using the LA PCR kit (Takara Bio) and the following primers: 5' -TGAAGGAGAGGAAGCCCTATCG-3' (forward) and $5^{\prime}$-TCACAAAGAAGCCGTCGTAGCC-3' (reverse). For the semiquantitative RT-PCR of the neighboring genes of the Ten-4 gene, cDNA was amplified with $30 \mathrm{PCR}$ cycles at $94^{\circ} \mathrm{C}$ for $30 \mathrm{~s}, 60^{\circ} \mathrm{C}$ for $30 \mathrm{~s}$, and $72^{\circ} \mathrm{C}$ for 1 min using the Ex-TaqDNA polymerase (Takara Bio) with the following primers: mouse LOC666836, 5'-AAGAAGTGCTCAGAGAGGTGGA AG-3' (forward) and 5'-TTGGGGGGGATGTAGGTTTTC-3' (reverse); mouse Nars2, 5' -GGTGAGACACTGTGGCAACATACC-3' (forward) and 5'-CCGATGAAAGGCAAAGCAGG-3' (reverse); and mouse Gab2, 5'-AT CGCCTCCCGAGAAGAAGTTG-3' (forward) and 5'-GCCGTTGATACA GTGTCCATTGC-3' (reverse). For quantitative RT-PCR, cDNA was amplified with an initial denaturation at $95^{\circ} \mathrm{C}$ for $15 \mathrm{~min}$ and then $45 \mathrm{PCR}$ cycles at $94^{\circ} \mathrm{C}$ for $10 \mathrm{~s}, 58.5^{\circ} \mathrm{C}$ for $30 \mathrm{~s}$, and $72^{\circ} \mathrm{C}$ for $30 \mathrm{~s}$ using the IQ SYBR Green Supermix (Bio-Rad) and gene-specific primers as follows: mouse MBP, 5' -GTCCAGGCTTCCTTTGTTTTCTTC-3' (forward) and 5' -CGTG TTCTCCTAAGTCCCCGTTTC-3' (reverse); mouse neurofilament heavy chain, $5^{\prime}$-GCTGAGAAACACCAAGTGGGAG-3' (forward) and 5' -AGAG AAGGGACTCGGACCAAAG-3' (reverse); mouse CNP, 5' -GGAGATGA ACCCAAGGAGAAGC-3' (forward) and 5'-GGTGTCACAAAGAGAGCA GAGATGG-3' (reverse); rat CNP, 5' -GTTCCTGACCAAAAAGAGTTCC G-3' (forward) and 5'-CACAAAGAGGGCAGAGATGGAC-3' (reverse); mouse and rat MAG, 5' -GCCTTTGCCATCCTGATTGC-3' (forward) and
5' -TCTGAGTGGGAATAACTGAGGTCC-3' (reverse); rat PLP, 5' -GGTC TTATGGCGTTCTGCTCTG-3' (forward) and 5'-CCATACATTCTGGC ATCAGCG-3' (reverse); mouse platelet-derived growth factor $\alpha$-receptor (PDGFR- $\alpha$ ), $5^{\prime}$-CGTCTGGTCCTATGGCATTCTG-3' (forward) and 5' TCTCTTCTCGGGCTCACTGTTC-3' (reverse); rat PDGFR- $\alpha$, $5^{\prime}$-GGTC TTATGGCGTTCTGCTCTG-3' (forward) and $5^{\prime}$-GGTCTCTTTTCGGG TTCACTGTTC-3' (reverse); ratTen-4,5'-GTGGACAAGTTTGGGCTCAT TTAC- $3^{\prime}$ (forward) and $5^{\prime}$-GGGTTGATGGCTAAGTCTGTGG-3' (reverse); mouse FAK, 5'-TGATGAAGCACCACCCAAGC-3' (forward) and $5^{\prime}$-ATCTCCTGAGGTCTGTGATTCCAC-3' (reverse); and mouse and rat GAPDH, $5^{\prime}$-CCACTAACATCAAATGGGGTGAGG-3' (forward) and 5'-TACTTGGCAGGTTTCTCCAGGC-3' (reverse).

Western blotting. Protein samples from tissues or cells were dissolved with LDS sample buffer (Invitrogen) containing $10 \mathrm{~mm}$ DTT. After sonication for $30 \mathrm{~s}$ three times, the samples were denatured at $70^{\circ} \mathrm{C}$ for 10 min. The denatured samples were analyzed using a $4-12 \%$ polyacrylamide Bis-Tris gel (Invitrogen). After electrophoresis, the proteins were transferred to a PVDF membrane (Invitrogen). The membrane was blocked with 5\% skim milk in Tris-buffered saline. Primary and secondary antibodies and SuperSignal West Dura Chemiluminescent Substrate (Thermo Fisher Scientific) were used to detect proteins. The following antibodies were used in Western blotting: Ten-4 (raised in a rabbit with a synthetic peptide, TETDHPSSLQNHPRLRT, from the intracellular domain encoded in exon 5 of the Ten-4 gene; National Center for Biotechnology Information Reference Sequence NP_035988.2), $\beta$-actin (Santa Cruz Biotechnology), FAK (Millipore), phospho-FAK (Tyr397) (Invitrogen), and rabbit IgG-HRP and mouse IgG-HRP (Cell Signaling Technology and Thermo Fisher Scientific).

Tissue sections. For histological analyses, mice were anesthetized with Avertin and perfused with 4\% paraformaldehyde in PBS. After perfusion, the spinal cords were dissected out and embedded in paraffin. The paraffin-embedded spinal cords were sectioned and attached to slides. Myelin was stained with Luxol fast blue (LFB).

Immunostaining. To immunostain the spinal cord tissue sections, the paraffin-embedded spinal cords were deparaffinized, and target retrieval was performed with Target Retrieval Solution (Dako). To immunostain cells in culture, cells were fixed with $4 \%$ paraformaldehyde and permeabilized with $0.1 \%$ Triton X-100. After target retrieval of the tissue samples and permeabilization of cell culture samples, the samples were blocked with Power Block Universal Blocking Reagent (BioGenex Laboratories). Proteins were detected by primary and secondary antibodies, as follows: MBP, NeuN, NG2, galactocerebroside (GalC), MAG, and interleukin-2 receptor (IL2R) (Millipore), neurofilament (Sigma-Aldrich), adenomatous polyposis coli (APC) (EMD Chemicals), perlecan (NeoMarkers), rabbit IgG-Cy3, mouse IgG-Cy3, and mouse IgG-Cy5 (Jackson ImmunoResearch), and rabbit IgG-Alexa Fluor 488, mouse IgG-Alexa Fluor 488, IgG-Alexa Fluor 647, and phalloidin-rhodamine (Invitrogen).

The epifluorescent images of immunostaining of tissues were obtained with an Axiophot upright microscope (Carl Zeiss), using a Plan-Neofluar $20 \times(0.5 \mathrm{NA})$ objective. Single-bandpass filter sets (Chroma Technology) for Alexa Fluor 488, Cy3, and DAPI were used for excitation and emission. Images were acquired with a Cool Snap CCD camera (Photometrics). MetaMorph was used to acquire images (Molecular Devices). Confocal microscopy images of immunostaining of cells were obtained using a Carl Zeiss LSM 510 NLO META confocal microscope equipped with A-Plan-Apochromat $63 \times(1.4 \mathrm{NA})$ or plan-Neofluar $40 \times(1.3 \mathrm{NA})$ objectives (Carl Zeiss). The $488 \mathrm{~nm}$ argon, $543 \mathrm{~nm}$ helium-neon 1, and 633 nm helium-neon 2 gas lasers were used to excite Alexa Fluor 488, rhodamine and $\mathrm{Cy} 3$, and $\mathrm{Cy} 5$ fluorophores, respectively. The pinholes for each laser line were aligned for optimal confocality. A titanium: sapphire 1.5 W Cameleon two-photon laser was used for DAPI illumination. The two-photon laser was tuned to $750 \mathrm{~nm}$ and used at $\sim 6 \%$ power. All confocal settings were set to the same parameters between each experiment.

In situ hybridization. Probes for the in situ hybridization of Ten-4 were prepared using the pCRII TOPO vector (Invitrogen), which has both the SP6 and T7 priming sites. A part of the Ten- 4 coding sequence, including exons $25-27$ of the Ten-4 gene, was amplified using the following primers: 5' ${ }^{\prime}$-TCCCCTTTGATGATACCCGC-3' (forward) and 5' ${ }^{\prime}$-TTCGGA 

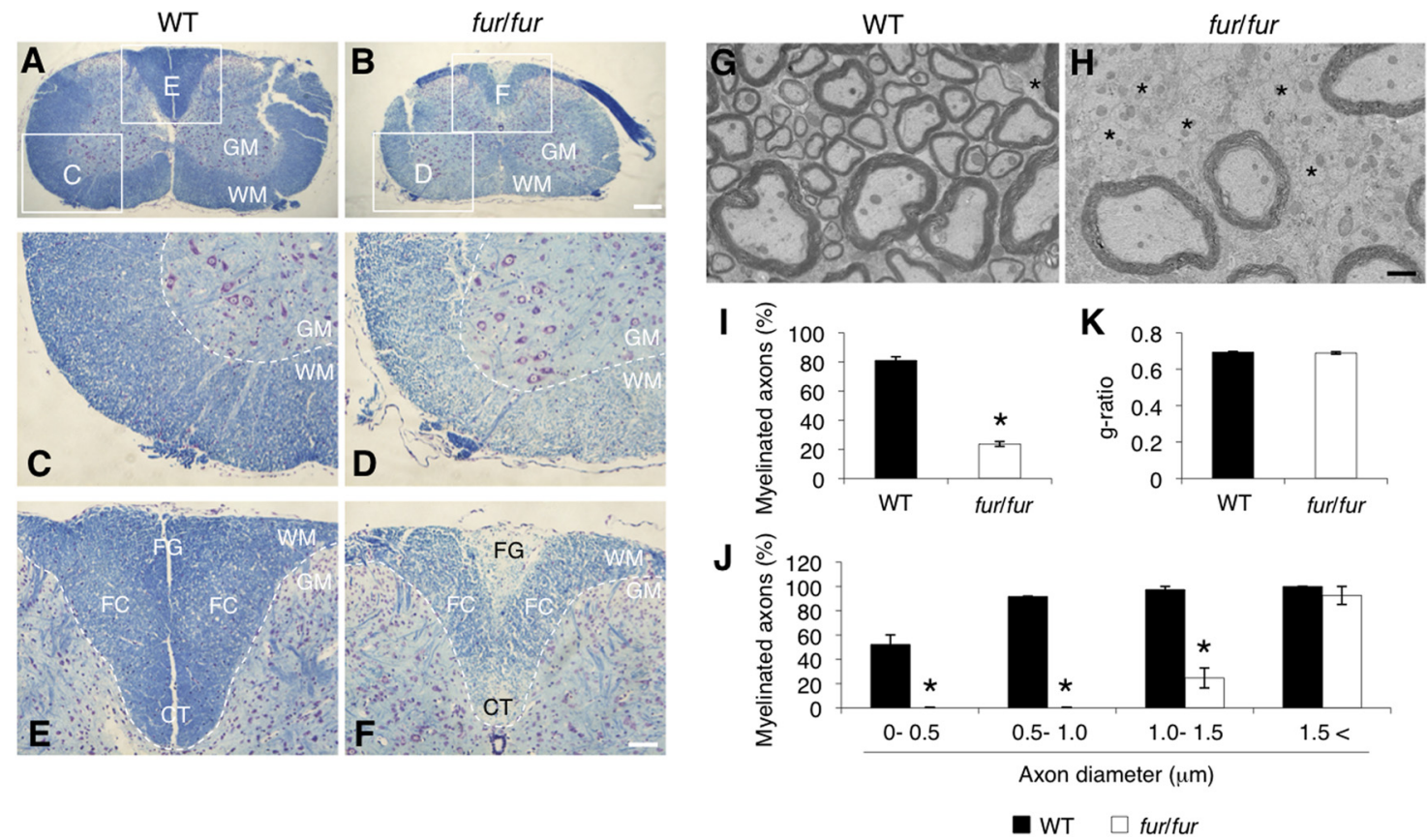

Figure 1. Defects in myelination in the spinal cord of fur/fur mice. $A, B$, LFB staining of the cervical spinal cords of 9-month-old WT and fur/fur mice. Myelin staining in the white matter was reduced in fur ffur mice. Higher-magnification images of the lateral $(\boldsymbol{C}, \boldsymbol{D})$ and dorsal $(\boldsymbol{E}, \boldsymbol{F})$ funiculus are shown. Severe defects in myelin formation were observed in the corticospinal tract and in the fasciculus gracilis of fur/fur mice. GM, Gray matter; WM, white matter; $\mathrm{CT}$, corticospinal tract; FG, fasciculus gracilis; FC, fasciculus cuneatus. Scale bars: low magnification, $200 \mu \mathrm{m}$; high magnification, $100 \mu \mathrm{m} . \mathbf{G}, \boldsymbol{H}$, EM analysis of myelination in the lateral funiculus of the cervical spinal cords of 7-week-old WT and fur/fur mice. There are many unmyelinated axons, especially small-diameter axons in fur/fur mice. Asterisk, Unmyelinated axon. Scale bar, $1 \mu \mathrm{m}$. I, Quantitative analysis of myelination in the spinal cords of WT and fur/fur mice. The percentage of myelinated axons was decreased in fur/fur mice. For quantification, three different littermates were used. Error bars indicate SEM; ${ }^{*} p<0.005$. J, Quantitative analysis of the myelination of smaller- and larger-diameter axons in the spinal cords of WT and fur/fur mice. The percentage of the myelinated small $(<1.5 \mu \mathrm{m})$ axons was reduced in the fur/fur mice, whereas no significant difference was observed in the myelination of large-diameter $(>1.5 \mu \mathrm{m})$ axons. For quantification, three different littermates were used. Error bars indicate SEM; ${ }^{*} p<0.001$. $\boldsymbol{K}$, Analysis of the $g$-ratio in the spinal cords of WT and fur/fur mice. There was no difference in the $g$-ratio. For quantification, three different littermates were used. Error bars indicate SEM.

TGTTTCCCAGGTCG-3' (reverse). The amplified DNA fragment was ligated into the pCRII vector (pCRII-Ten-4). Digoxigenin (DIG)labeled single-strand RNA probes were prepared using pCRII-Ten-4, DIG RNA Labeling Mix (Roche Applied Science), and SP6 and T7 RNA polymerases (Roche Applied Science). After deparaffinization of the tissue sections, in situ hybridization was performed using the probes and In Situ Hybridization Detection System Core Kits (BioGenex Laboratories).

Ultrastructural analysis by electron microscopy. Seven-week-old mice were anesthetized and perfused with $4 \%$ paraformaldehyde in $0.1 \mathrm{M}$ PIPES buffer, $\mathrm{pH}$ 7.35. After perfusion, the spinal cords, the brains, and the sciatic nerves were dissected out and postfixed with $2 \%$ paraformaldehyde and $2.5 \%$ glutaraldehyde in $0.1 \mathrm{M}$ PIPES buffer, $\mathrm{pH} 7.35$, including $2 \mathrm{~mm} \mathrm{CaCl}$. After postfixation, the tissues were embedded in Epon resin and thin sectioned. The cross-sections of the lateral funiculus in the spinal cords, the corpus callosum in the brains, and the entire sciatic nerves were analyzed. For the myelination analysis, NIH Image J software was used.

Fluorescent in situ hybridization and spectral karyotyping. Samples for fluorescent in situ hybridization (FISH) and spectral karyotyping (SKY) were prepared from the furl+ and fur/fur splenocytes. FISH and SKY were performed as described previously (Matsui et al., 2002). A probe, including the entire transgene, was prepared by NotI digestion of p3108FC.

Southern blotting. Five micrograms of genomic DNA was digested with SacI, which generates the 5.9 and $5.1 \mathrm{~kb}$ bands from intron 5 of the Ten- 4 gene in the wild-type (WT) and fur alleles, respectively. After electrophoresis, genomic DNA was transferred to a nylon membrane using TurboBloter (Whatman Schleicher and Schuell). A DNA probe was prepared by PCR using the following primers: 5'-GCGTTGCCAGCAGAGAAAAT AC-3' (forward) and 5'-GGTCTCTCTTCATCCTACATCACCC-3' (reverse). The probe was labeled with ${ }^{32} \mathrm{P}$ using DNA Labeling Beads (-dCTP) (GE Healthcare). Hybridization was performed using the membrane and the ${ }^{32} \mathrm{P}$-labeled probe in the PerfectHyb Plus Hybridization Buffer (Sigma-Aldrich) overnight at $65^{\circ} \mathrm{C}$.
Cell culture. The rat OPC line CG-4 was kindly provided by Dr. Franca Cambi (University of Kentucky, Lexington, KY) and Dr. Tadashi Yamamoto (University of Tokyo, Tokyo, Japan). CG-4 cells were plated on poly-Lornithine-coated dishes and cultured in DMEM (Invitrogen)/N1 medium [5 $\mu \mathrm{g} / \mathrm{ml}$ transferrin (Sigma-Aldrich), $100 \mu \mathrm{M}$ putrescine (Sigma-Aldrich), 200 nм progesterone (Sigma-Aldrich), 470 nм selenium (Sigma-Aldrich), 5 $\mu \mathrm{g} / \mathrm{ml}$ insulin (Sigma-Aldrich), $10 \mu \mathrm{g} / \mathrm{ml}$ biotin (Sigma-Aldrich), $2 \mathrm{~mm}$ L-glutamine (Invitrogen), and $100 \mathrm{U} / \mathrm{ml}$ penicillin and $100 \mu \mathrm{g} / \mathrm{ml}$ streptomycin (Invitrogen)] supplemented with $30 \%$ conditioned medium of the rat neuroblastoma cell line B104. For differentiation, CG- 4 cells were cultured in the differentiation medium [DMEM/N1 medium with $40 \mathrm{ng} / \mathrm{ml}$ triiodo-Lthyronine $\left(\mathrm{T}_{3}\right.$; Sigma-Aldrich) ]. This concentration of $\mathrm{T}_{3}$ is within the optimal range for oligodendrocyte differentiation (Emery et al., 2009; Horiuchi et al., 2010).

For primary mixed glial cell culture, newborn WT and furlfur brains were dissected and digested with papain (Worthington) and DNase (Sigma-Aldrich). After digestion, cells were prepared as described previously (Horiuchi et al., 2010). The cells were then plated on poly-Lornithine-coated culture dishes in DMEM including 10\% fetal bovine serum. One day after cells were plated, the medium was changed to the OPC medium [DMEM/N1 medium, containing 30\% B104 conditioned medium, $5 \mathrm{ng} / \mathrm{ml} \mathrm{FGF2} \mathrm{(PeproTech),} \mathrm{and} 20 \mu \mathrm{M}$ forskolin (SigmaAldrich)] to enrich OPCs. After $4 \mathrm{~d}$ of culture in the OPC medium, differentiation of OPCs was induced by the differentiation medium for $4 \mathrm{~d}$.

shRNA. For knockdown of Ten-4, the pGIPZ shRNAmir vector, which contains the targeting sequence of Ten-4 (Thermo Fisher Scientific), was used. The control was non-silencing-GIPZ shRNAmir (Thermo Fisher Scientific). The vectors were transfected into CG-4 cells with Lipofectamine LTX (Invitrogen) or the Nucleofector 96-well Shuttle System (Lonza). The transfected CG-4 cells were cultured in the presence of 500 $\mathrm{ng} / \mathrm{ml}$ puromycin until all the nontransfected cells had died. After the transfected cells were selected with puromycin, the transfected CG-4 cells were used for each experiment. 

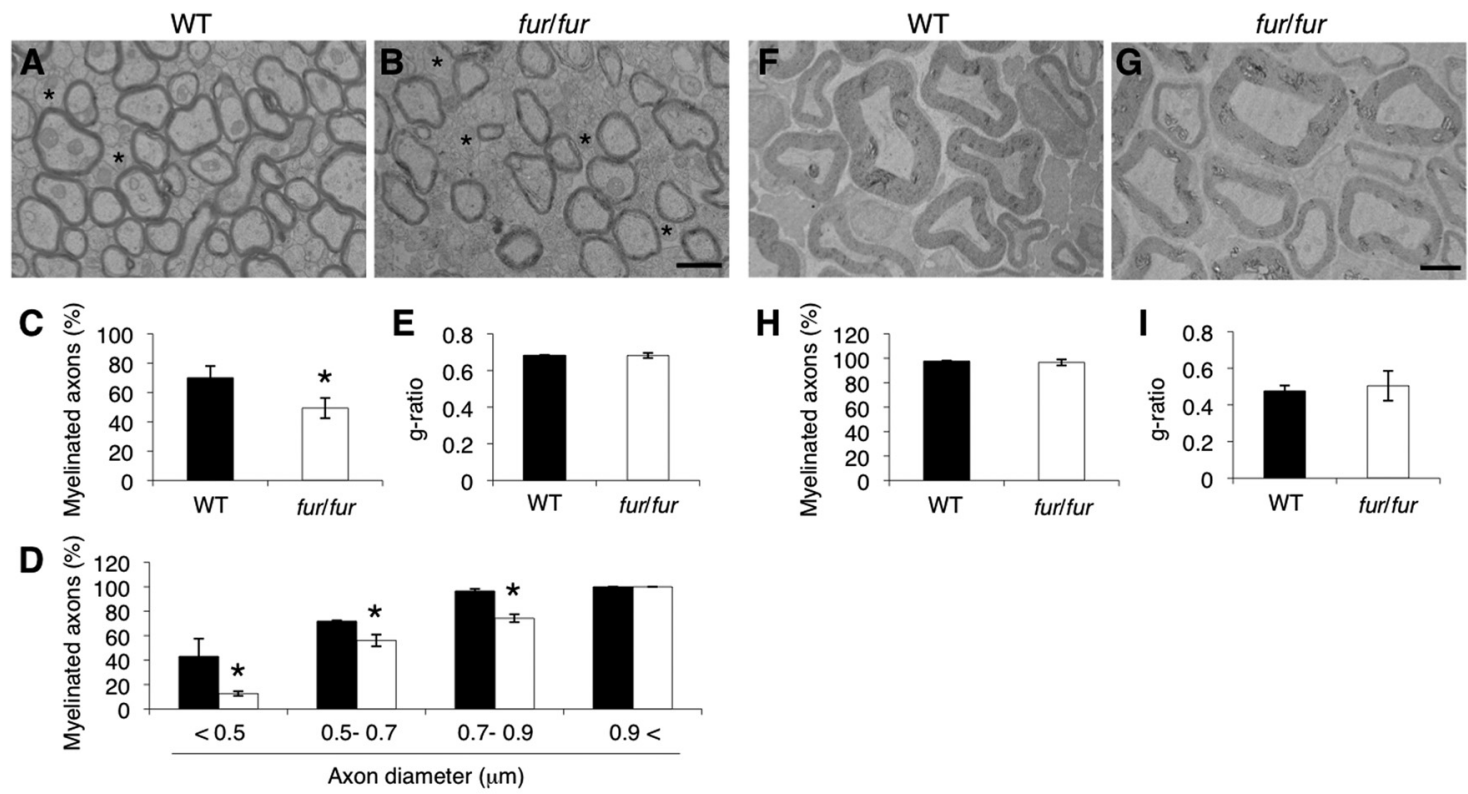

WT $\square$ furlfur

Figure 2. Defects in the myelination of the CNS, but not PNS, of fur/fur mice. $\boldsymbol{A}, \boldsymbol{B}$, EM analysis of myelination in the corpus callosum of 7-week-old WT and fur/fur mice. The number of unmyelinated axons was increased in fur/fur mice. Asterisk, Unmyelinated axon. Scale bar, $1 \mu \mathrm{m}$. C, Quantitative analysis of myelination in the corpus callosum of WT and fur/fur mice. The percentage of myelinated axons was reduced in the fur/fur mice. For quantification, three different littermates were used. Error bars indicate SEM; ${ }^{*} p<0.005$. $\boldsymbol{D}$, Quantitative analysis of the myelination of small- and large-diameter axons in the corpus callosum of WT and fur/fur mice. The percentage of myelinated small-diameter (<0.9 $\mu \mathrm{m}$ ) axons was slightly decreased in the fur/fur mice, whereas no significant difference was observed in the myelination of large-diameter $(>0.9 \mu \mathrm{m})$ axons. For quantification, three different littermates were used. Error bars indicate $S E M$; ${ }^{*} p<$ 0.02. $\boldsymbol{E}$, Analysis of $g$-ratio in the corpus callosum of WT and fur/fur mice. There was no difference in the $g$-ratio. For quantification, three different littermates were used. Error bars indicate $S$ EM. $\boldsymbol{F}$, $\mathbf{G}$, EM analysis of myelination in the sciatic nerve of 7-week-old WT and fur/fur mice. In the sciatic nerve of fur/fur mice, myelination normally occurred. Scale bar, $2 \mu \boldsymbol{m}$. $\boldsymbol{H}$, Quantitative analysis of myelination in the sciatic nerve of WT and fur/fur mice. No significant difference was observed. For quantification, three different littermates were used. Error bars indicate SEM. $I$, Analysis of $g$-ratio in the sciatic nerve of WT and fur/fur mice. There was no difference in the $g$-ratio. For quantification, three different littermates were used. Error bars indicate SEM.

Analysis of cell morphology. Confocal images of primary oligodendrocytes and CG-4 cells were taken to discern cell branching and the cell area. All image analysis was performed using MetaMorph 7.5 (Molecular Devices). Actin images were further filtered using an unsharp mask $(5 \times 5$, scaling factor of 0.6 ), followed by a $3 \times 3$ median filter. To measure cell areas of GalC-positive cells in the primary culture and CG-4 cells, NIH Image J software was used. Eight-bit grayscale images were created, and the signal from the GalC or actin staining was thresholded. The cell area was measured by counting particles of the signal. To quantify branching of cell processes in GalC-positive cells, concentric circles were made and numbered $1-3$, as shown in Figure $5 C$ and described previously (Rajasekharan et al., 2009). Intersections between the processes and the circles were counted, and the results were then thresholded manually. For analysis of phalloidin staining of MAG-positive CG-4 cells, a 16-bit version of the 8-bit image was created, and a region of interest was drawn around single cells. The angiogenesis tube formation application was run on the final image to determine the cell area and the number of branches per cell.

Constructs of constitutively active and dominant-negative FAK. The plasmids of constitutively active FAK (CA-FAK), which consists of the extracellular and transmembrane domains of human IL2R and mouse FAK, and the plasmids of dominant-negative FAK (DN-FAK), which possesses a phenylalanine substitution in the tyrosine 397 residue of CA-FAK, were kindly provided by Dr. Kenneth M. Yamada (National Institute of Dental and Craniofacial Research, NIH, Bethesda, MD) (Katz et al., 2002). These plasmids were cotransfected with the pGIPZshRNAmir vector for Ten-4 into CG-4 cells using the Neon Transfection System (Invitrogen).

\section{Results}

\section{Generation of the mutant fur/fur mice}

One line of transgenic mice, expressing recombinant perlecan (a heparan sulfate proteoglycan) specifically in cartilage, developed severe tremors in the hindlimbs $\sim 4$ weeks after birth (see Notes).
The tremors were observed in the transgene-homozygous mice when the mice were walking but not when they were resting (see supplemental movie, http://www.youtube.com/watch?v=bcmcjLuB_ bs). On rare occasions, paralysis in the hindlimbs occurred. The body size and weight of the transgene-homozygous mice were reduced compared with WT and transgene-heterozygous mice. The onset of the reduced body size and weight occurred in the early postnatal stages. The tremors, paralysis, and reduced body size were not observed in the other transgenic mouse line, suggesting that these phenotypes were unique and may be attributable to the disruption of an endogenous gene by the transgene insertion. We designated this mutation " $f u$ rue" (from the Japanese term, furue, for tremor). According to the guidelines for nomenclature (http://www.informatics. jax.org/mgihome/nomen/), the name of this mutant allele is furue $e^{T g(H s p g 2) 2 Y y}$, hereafter referred to as fur. Because fur/fur mice may be useful as animal models for understanding neurological disorders, we further characterized these mutants.

\section{Hypomyelination in the CNS of fur/fur mice}

Because severe defects in myelination in the CNS are commonly observed in mutant mice with tremors (Griffiths, 1996), we first examined formation of myelin in the CNS of adult fur/fur mice using LFB staining. In the white matter of the fur/fur spinal cord, the myelin formation was reduced and the area of the white matter was smaller than that observed in WT mice (Fig. $1 A-F$ ). In the dorsal funiculus of the fur/fur spinal cord, the defect in myelin formation was more severe in the corticospinal tract (Fig. $1 E, F$, indicated as $\mathrm{CT}$ ) and the fasciculus gracilis (Fig. 1 E, F, indicated as FG) compared with defects in the fasciculus cuneatus (Fig. $1 E, F$, indicated as FC). The corticospinal tract is one of the major motor tracts, and the 
A
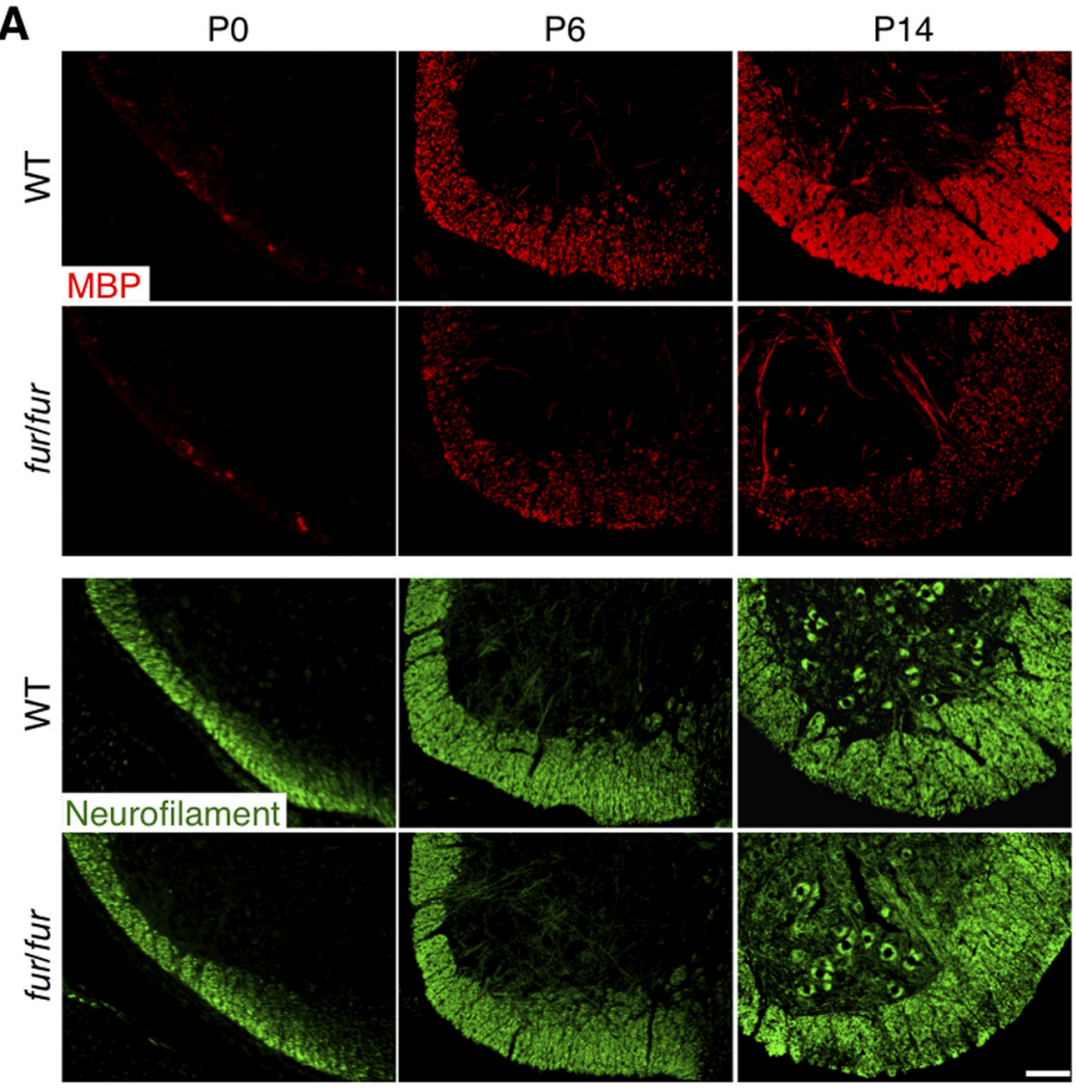

C

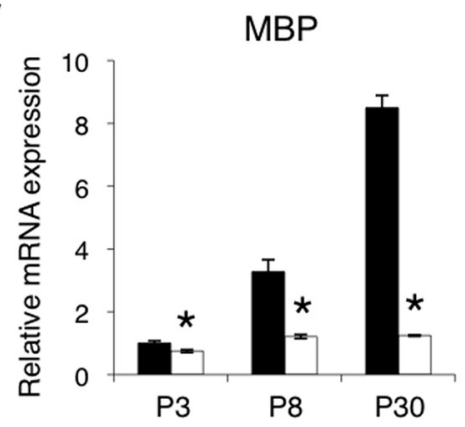

D

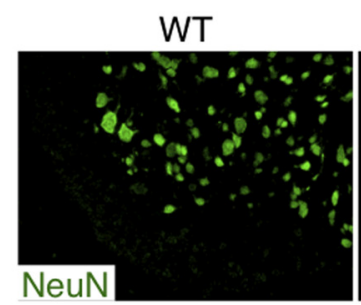

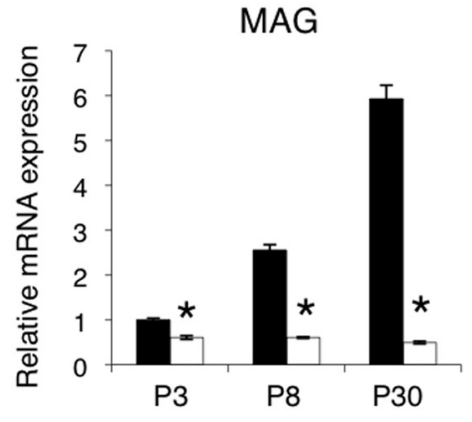

- WT $\square$ furlfur
B
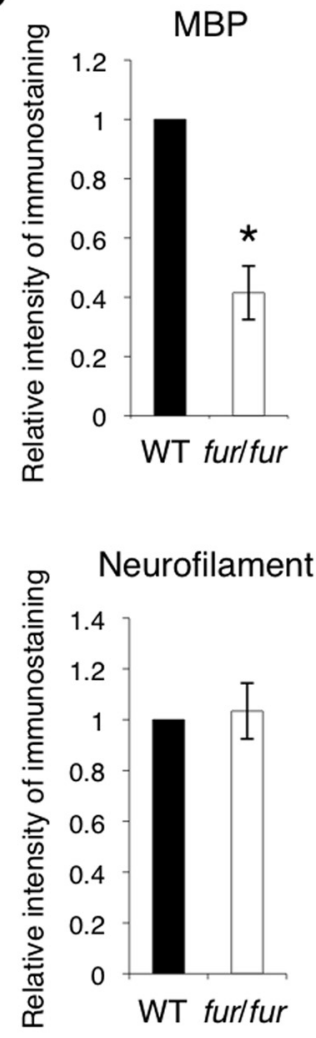

Neurofilament

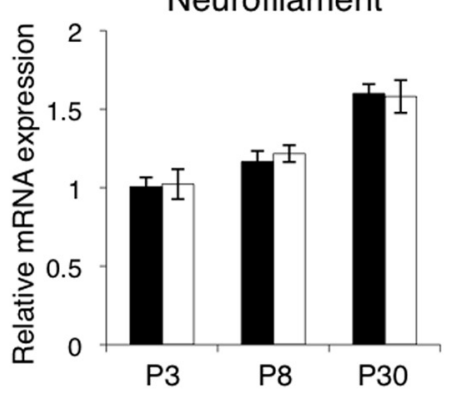

Figure 3. Reduced expression of MBP in the spinal cord of fur/fur mice. A, Immunostaining of MBP and neurofilament in the spinal cords of WT and fur/fur mice in the early postnatal stages. MBP staining was reduced in fur/fur mice at P6 and P14, whereas there was no significant difference in neurofilament staining. Scale bar, $100 \mu \mathrm{m}$. $\boldsymbol{B}$, Quantitative analysis of the intensity of MBP and neurofilament immunostaining in the spinal cords of WT and fur/fur mice at P5-P7. The expression of the MBP protein was reduced in the fur/fur mice. For quantification, three different littermates were used. The normalized expression of each protein in the WT mice was set as 1.0. Error bars indicate SEM; ${ }^{*} p<0.02$. C, Quantitative RT-PCR of MBP, MAG, and neurofilament in the spinal cords of WT and fur/fur mice at various stages. mRNA expression levels of MBP and MAG in fur/fur mice were reduced during all postnatal stages. In contrast, neurofilament mRNA expression was normal in fur/fur mice at the stages. The mRNA expression of each gene was normalized using GAPDH mRNA expression. The normalized expression of each gene in the WT mice at P3 was set as 1.0. Error bars indicate SEM; ${ }^{*} p<0.02$. D, Immunostaining of NeuN in the spinal cords of WT and fur/fur mice at P6. No significant difference was observed in NeuN staining. Scale bar, $100 \mu \mathrm{m}$. 
A PO

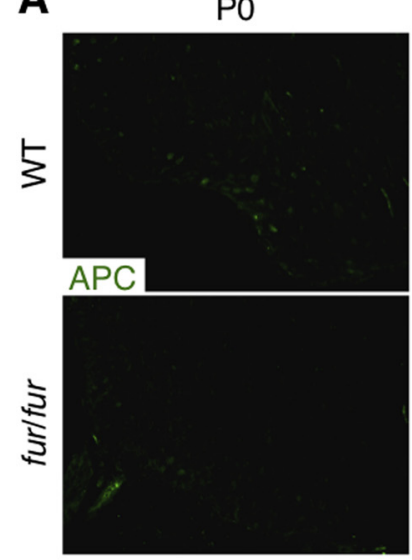

B

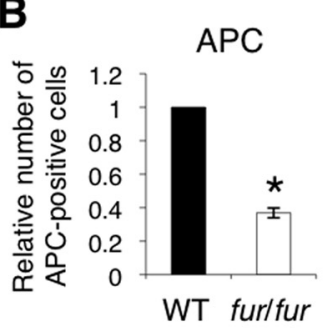

P6

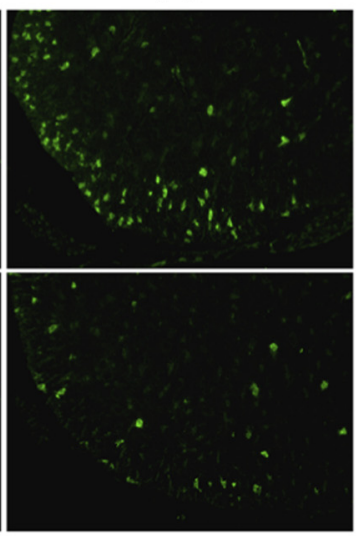

P0

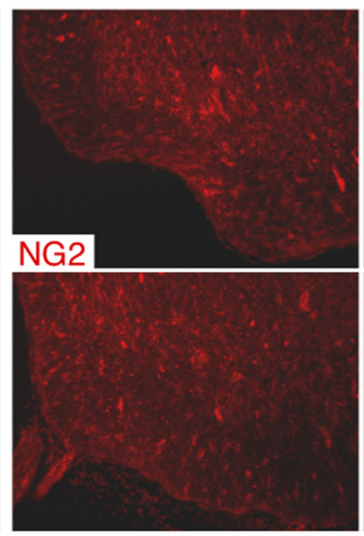

P6

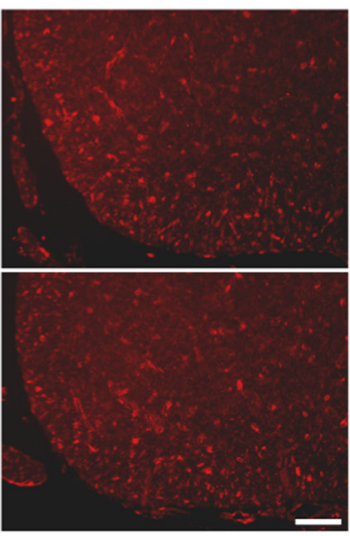

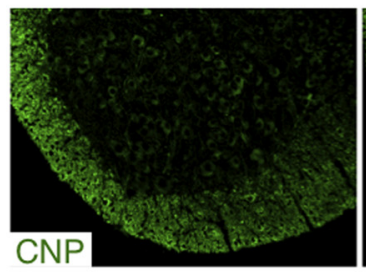

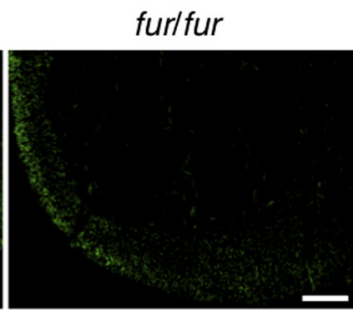

\section{D}

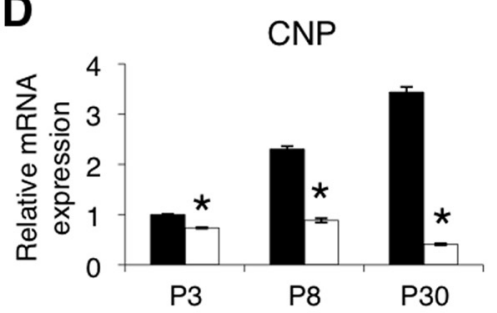

NG2

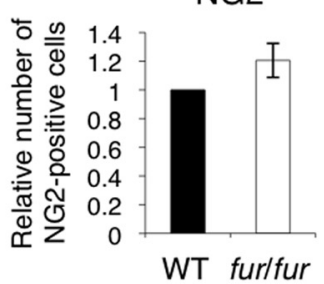

C WT

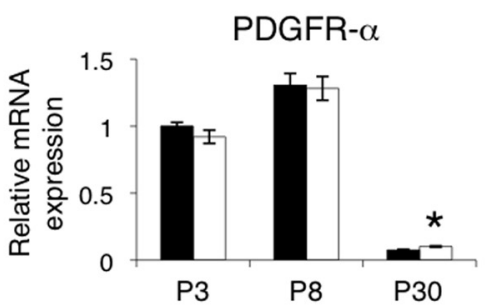

WT

$\square$ furlfur

$\mathbf{E}$
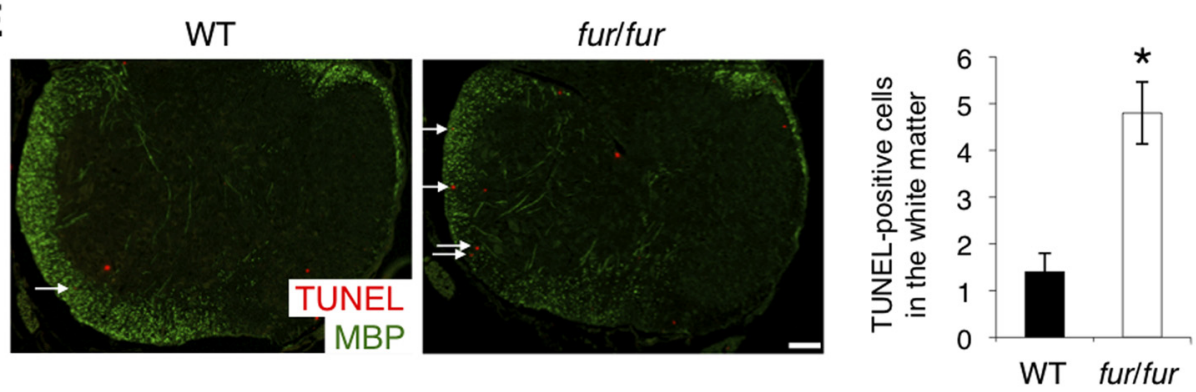

Figure 4. Defects in oligodendrocyte differentiation and survival in the spinal cord of fur/fur mice. $A$, Immunostaining of APC and NG2 in the spinal cords of WT and fur/fur mice at P0 and P6. The number of APC-positive cells was reduced in the fur/fur mice at P6, whereas no significant difference was observed in NG2 staining. Scale bar, $100 \mu \mathrm{m}$. B, The number of APC-and NG2-positive cells in the spinal cords of WT and fur/fur mice at P5-P7. APC-positive cells were significantly reduced in the fur/fur mice. For quantification, three different littermates were used. The normalized cell number in the WT mice was set as 1.0. Error bars indicate SEM; ${ }^{*} p<0.001$. C, Immunostaining of CNP in the spinal cords of WT and fur/fur mice at P7. The CNP protein expression was reduced in the fur/fur spinal cord. Scale bar, $100 \mu \mathrm{m}$. D, Quantitative RT-PCR of CNP and PDGFR- $\alpha$ in the spinal cords of WT and fur/fur mice at various stages. The mRNA expression of CNP was reduced in fur/fur mice during all postnatal stages. There was no difference in PDGFR- $\alpha$ mRNA expression in P3 and P8 fur/fur mice, whereas expression decreased in both the WT and fur/fur spinal cord at P30. The mRNA expression of each gene was normalized using GAPDH mRNA expression. The normalized expression of each gene in the WT mice at P3 was set as 1.0. Error bars indicate SEM; ${ }^{*} p<0.02$. $\boldsymbol{E}$, TUNEL assays in the spinal cords of WT and fur/fur mice at P6. The number of TUNEL-positive cells in the white matter was increased in the fur/fur mice at P6. Arrows, TUNEL-positive cells in the white matter. Scale bar, $100 \mu \mathrm{m}$. Error bars indicate SEM; ${ }^{*} p<0.02$.

fasciculus gracilis and cuneatus are the regions in which sensory axons from lower and upper bodies ascend, respectively. The pronounced defects in the fasciculus gracilis may be related to the hindlimb-dominant phenotype in fur/fur mice.

Electron microscopy analysis revealed that myelinated axons were significantly decreased in the lateral funiculus of the fur/fur spinal cord (Fig. 1G-I). We found that myelination, particularly in axons with smaller diameter $(<1.5 \mu \mathrm{m})$, was dramatically reduced in fur/fur mice (Fig. $1 \mathrm{~J}$ ). In contrast, there was no obvious difference in the myelination of larger-diameter axons $(>1.5$ $\mu \mathrm{m}$ ) between the WT and fur/fur spinal cord (Fig. 1G, H,J). We also analyzed the thickness of myelin using the $g$-ratio, which is 
A
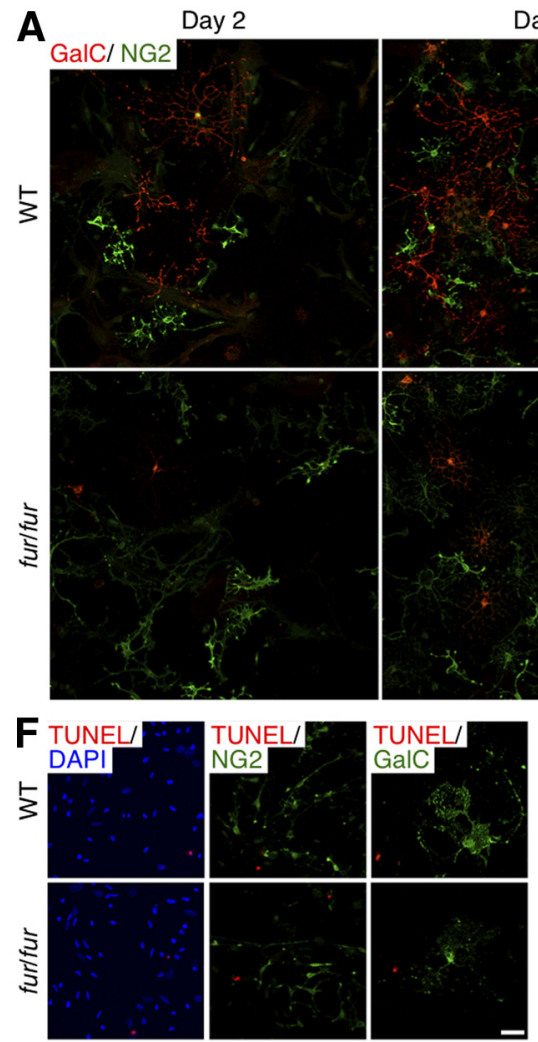

Day 4
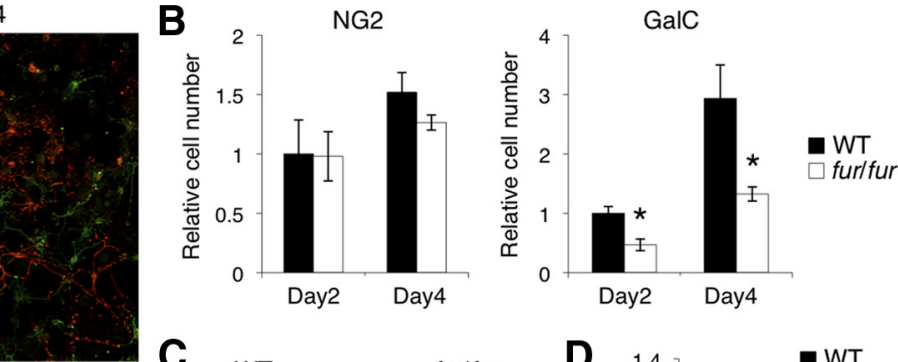

C
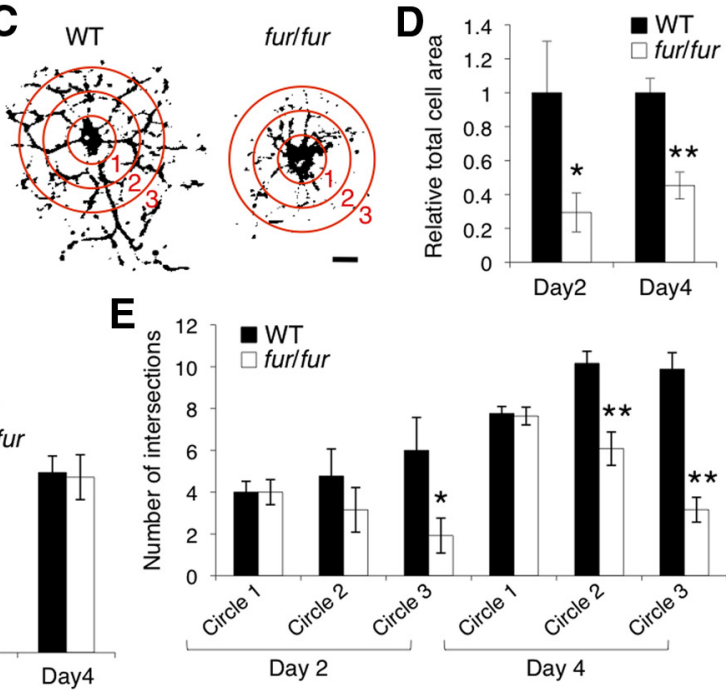

Figure 5. Reduced oligodendrocyte differentiation and cell process formation, but not survival, in primary cell culture from fur/fur mice. $\boldsymbol{A}$, Immunostaining of GaIC and NG2 in the primary culture from the WT and fur/fur brains after induction of differentiation. Scale bar, $10 \mu \mathrm{m}$. B, The relative number of NG2-and GalC-positive primary cells from WT and fur/fur mice 2 and $4 \mathrm{~d}$ after induction of differentiation. The number of GalC-positive cells was significantly reduced in fur/fur mice. Error bars indicate SEM; ${ }^{*} p<0.05$. C, Morphology of GaIC-positive cells in WT and fur/furprimary culture $4 \mathrm{~d}$ after induction of differentiation. GalC-positive oligodendrocytes from fur/fur mice displayed a reduction in cellular process formation. Typical morphology of WT and fur/fur GalC-positive cells is shown. Red concentric circles 1-3 were used to analyze branching of cellular processes ( $\boldsymbol{E}$ ). Scale bar, $2 \mu \mathrm{m}$. D, Quantification of the relative total cell area of GalC-positive cells in WT and fur/fur culture 2 and $4 \mathrm{~d}$ after induction of differentiation. The fur/fur GalC-positive cells had a smaller total cell area than that of WT GalC-positive cells. The normalized cell area in the WT GalC-positive cells was set as 1.0. Error bars indicate SEM; ${ }^{*} p<0.05 ;{ }^{* *} p<0.0001$. E, The branching of cell processes in GalC-positive WT and fur/fur cells 2 and $4 \mathrm{~d}$ after induction of differentiation. The branching of the processes in the fur/fur cells was reduced compared with that in the WT cells. Intersections between the cell processes and the concentric circles (Fig. $5 \mathrm{C}$ ) were counted. Error bars indicate SEM; ${ }^{*} p<0.05 ;{ }^{* *} p<0.0002$.F, TUNEL assays with DAPI, NG2, and GaIC staining in the primary culture from the WT and fur/fur brains $2 \mathrm{~d}$ after induction of differentiation. There was little signal of TUNEL on both NG2- and GalC-positive cells. Scale bar, $10 \mu \mathrm{m}$. G, The ratio of TUNEL-positive cells to DAPI stains in the primary culture of WT and fur/fur mice 2 and $4 \mathrm{~d}$ after induction of differentiation. There was no difference in the number of TUNEL-positive cells. Error bars indicate SEM.

the ratio of the diameter of axons to the diameter of outer myelin membrane circles (Chomiak and $\mathrm{Hu}, 2009$ ). It was not possible to measure the $g$-ratio of the smaller-diameter axons because of the severe myelination defect in the fur/fur spinal cord (Fig. 1J), whereas the $g$-ratio of myelinated large-diameter axons in the spinal cord of fur/fur mice was normal (WT, $0.694 \pm 0.004$; furl fur, $0.689 \pm 0.007$ ) (Fig. $1 K$ ). In the corpus callosum, the myelination of smaller-diameter $(<0.9 \mu \mathrm{m})$ axons was slightly reduced in fur/fur mice, whereas normal myelination was observed in larger-diameter $(>0.9 \mu \mathrm{m})$ axons, similar to that in the spinal cord (Fig. 2A-D). The $g$-ratio of myelinated axon fibers in the corpus callosum was similar (WT, $0.681 \pm 0.004$; fur/fur, $0.682 \pm 0.014$ ) (Fig. $2 E$ ). However, in the sciatic nerve of the PNS, there was no difference between myelination of the WT and fur/fur mice, including the g-ratio (WT, $0.476 \pm 0.030$; fur/fur, $0.504 \pm 0.081$ ) (Fig. $2 F-I$ ). These results suggest that myelination in the CNS, particularly in the spinal cord, was defective in furlfur mice, whereas PNS myelination in the sciatic nerve occurred normally.

We next analyzed the expression of MBP, a major component of myelin, and neurofilament, a marker for axons, in the spinal cord of fur/fur mice on postnatal day 0 (P0), P6, and P14. In the WT spinal cord, MBP expression was initially observed with a low level at P0, and its expression levels continuously increased at P6 and P14 (Fig. 3A). In contrast, the expression of MBP in the fur/fur spinal cord was significantly reduced at P6 and P14 compared with that in the WT spinal cord (Fig. $3 A, B$ ). The expression level of neurofilament was similar between the WT and fur/fur spinal cord during these stages (Fig. $3 A, B$ ). Quantitative RT-PCR analysis also revealed that the level of mRNA expression for MBP and MAG, another myelin marker protein, was reduced in the fur/fur spinal cord at P3, P8, and P30 compared with its expression in the WT spinal cord (Fig. 3C). However, no difference in the neurofilament mRNA expression levels was observed at P3, P8, or P30 (Fig. 3C). In addition, no obvious difference was detected in the immunostaining of NeuN, a marker for neuronal nuclei, in the gray matter of the spinal cord at P6 (Fig. 3D). Thus, the defect in myelin formation occurred in early postnatal stages, whereas neurons, including axons, were normal in the fur/fur spinal cord.

\section{Defects in oligodendrocyte differentiation in fur/fur mice}

During the early postnatal stages, OPCs in the WT spinal cord differentiate to oligodendrocytes, producing myelin. To determine whether the hypomyelination in fur/fur mice is caused by defects in oligodendrocyte differentiation, we used immuno- 
A
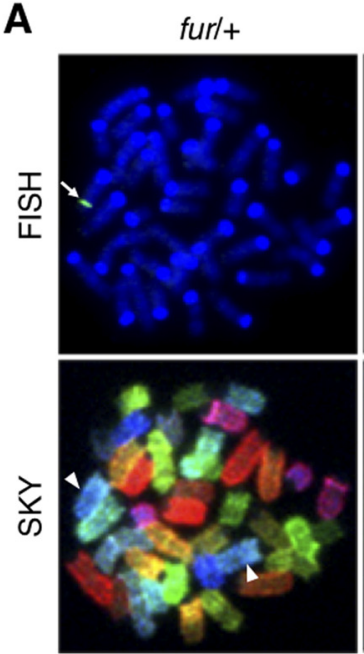

B
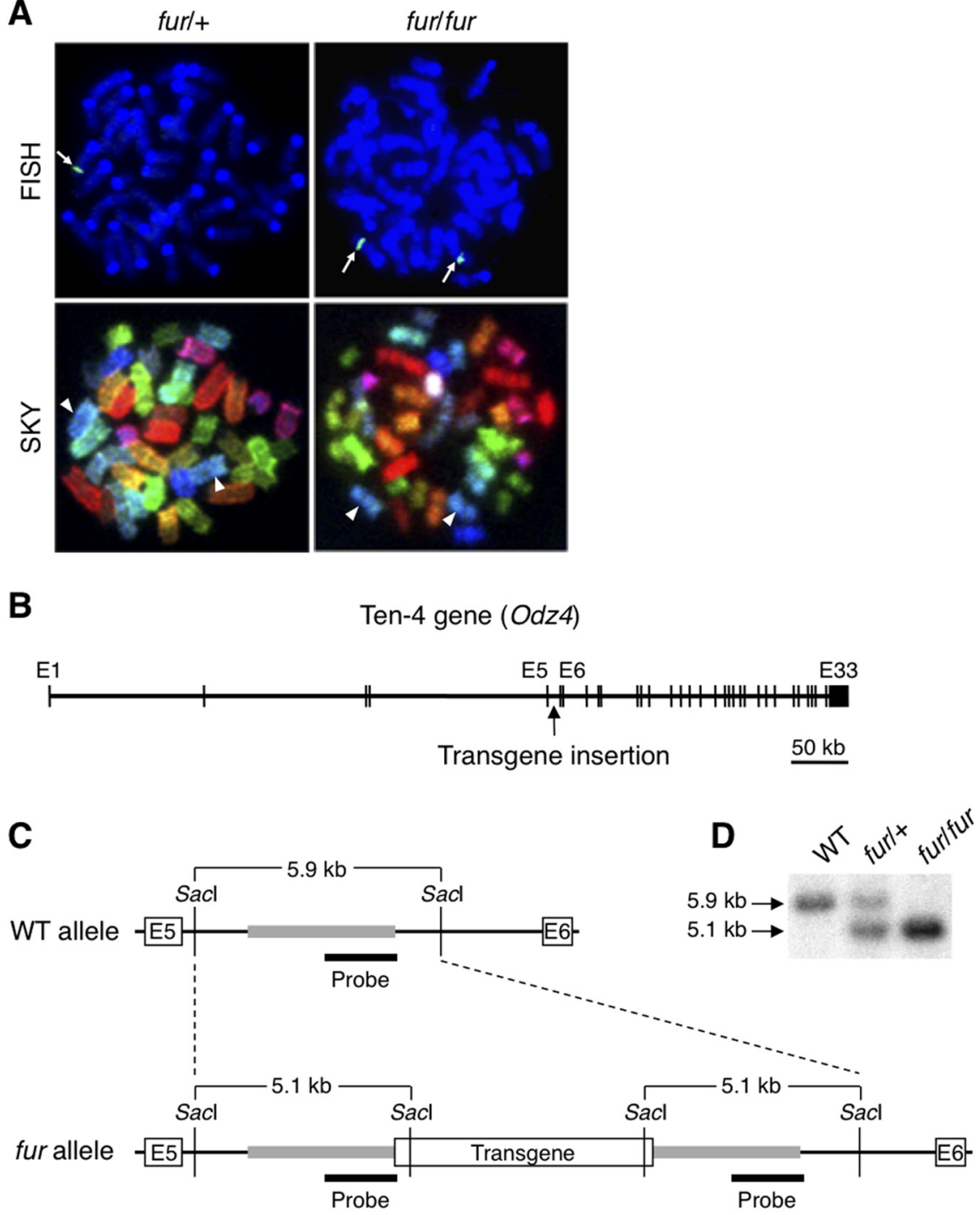

Figure 6. Transgene insertion into the Ten-4 gene in the fur allele. $A$, Location of the transgene insertion site on chromosome 7 of the fur allele. A single signal of the transgene was detected in one chromosome 7 of fur/ + mice by FISH and SKY. The signal was observed in both chromosomes 7 of fur/fur mice. Arrows, Transgene insertion site; arrowheads, chromosome 7. B, Location of the transgene insertion in the Ten-4 (0dz4) gene. The Ten- 4 gene is $\sim 700 \mathrm{~kb}$ in size and contains 33 exons. The transgene was inserted into intron 5 of the Ten- 4 gene. E, Exon. $\boldsymbol{C}$, Restriction maps of intron 5 of the Ten- 4 gene in WT and fur alleles. The transgene was inserted in the middle of intron 5 . A flanking region $(\sim 3 \mathrm{~kb})$ of the transgene was duplicated in the fur allele (gray bars). Sacl digestion and a probe (black bars) were used in Southern blotting. E, Exon. D, Genotyping by Southern blotting. The 5.9 and $5.1 \mathrm{~kb}$ bands are from the WT and fur alleles, respectively. Note that, in the middle lane, blotting DNA from heterozygous fur/+ mice showed higher intensity of the $5.1 \mathrm{~kb}$ band for the fur allele compared with the $5.9 \mathrm{~kb}$ WT allele because of the duplication of the $3 \mathrm{~kb}$ flanking regions of the transgene.

staining to examine the expression of APC and NG2 as markers for oligodendrocytes and early OPCs, respectively. Numbers of APC-positive cells were reduced in the fur/fur spinal cord at P6 compared with those in the WT spinal cord (Fig. 4A,B). However, no significant difference was found in numbers of NG2-positive cells (Fig. $4 A, B$ ). To further examine which differentiation stage is affected by the fur/fur mutation, P7 spinal cords were immunostained with $\mathrm{CNP}$, one of the early markers, which include $\mathrm{GalC}$ and is expressed earlier than APC, MAG, and MBP during oligodendrocyte differentiation. CNP was expressed strongly in the white matter of the WT spinal cord, whereas its expression was substantially reduced in the fur/fur spinal cord (Fig. 4C). Quantitative RT-PCR analysis showed that CNP mRNA was expressed in the WT spinal cord at P3, and its expression levels were increased at P8 and P30
(Fig. 4D). However, in the fur/fur spinal cord, CNP mRNA expression was reduced from $\mathrm{P} 3$, at which stage oligodendrocyte differentiation had been started. In contrast, the mRNA expression level of PDGFR- $\alpha$, another progenitor marker whose expression appears later than NG2 expression, was the same in the spinal cord between WT and fur/fur mice (Fig. 4D). These results suggest that, in fur/fur mice, OPCs were formed, but their differentiation was inhibited. We also found that the number of TUNELpositive cells in the white matter of the spinal cord was increased in fur/fur mice (Fig. $4 E$ ), indicating that survival of oligodendrocytes may have been also defective in fur/fur mice.

\section{Reduced differentiation and cell process formation of oligodendrocytes in the fur/fur primary cell culture}

We further analyzed oligodendrocyte differentiation using the primary cell culture from fur/fur mice. Primary OPCs were induced to differentiate for $4 \mathrm{~d}$ in the differentiation medium with $\mathrm{T}_{3}$ thyroid hormone. During differentiation, no difference in the number of NG2-positive progenitor cells was observed between WT and fur/fur cells (Fig. 5A,B). However, we observed reduced numbers of GalC-positive early differentiated oligodendrocytes in the fur/fur culture both 2 and $4 \mathrm{~d}$ after induction of differentiation compared with those in the WT culture (Fig. 5A,B). These results were consistent with in vivo observations (Fig. 4). Furthermore, we found that cell morphology of the fur/fur GalC-positive cells was distinct from that of WT cells (Fig. 5C) with reduced cellular processes. The total cell area and branching of cellular processes in the fur/fur GalC-positive cells were lower both 2 and $4 \mathrm{~d}$ after induction of differentiation (Fig. $5 D, E$ ). The decrease in both the total cell area and the branching in the fur/fur cells at day 4 (cell area, $p<0.0001$; branching, $p<0.0002$ ) was statistically more significant than that the decrease at day 2 (cell area, $p<0.05$; branching, $p<0.05$ ) (Fig. $5 D, E$ ). These results suggest that the defect in cellular process formation observed in the fur/fur cells was not attributable to a delay in differentiation but likely was attributable to inability of the fur/fur cells to form cellular processes.

In addition, we examined cell survival in the primary culture 2 and $4 \mathrm{~d}$ after the induction of differentiation. There was no difference in the number of TUNEL-positive cells between WT and fur/fur cultures (Fig. 5F,G). TUNEL-positive signals in either NG2-positive progenitors or GalC-positive oligodendrocytes were hardly observed $2 \mathrm{~d}$ after the induction of differentiation (Fig. $5 F$ ). Four days after the induction of differentiation, there was no difference in the ratio of TUNEL and NG2 doublepositive cells to total cells (WT, $0.050 \pm 0.003$; fur/fur, $0.052 \pm$ 


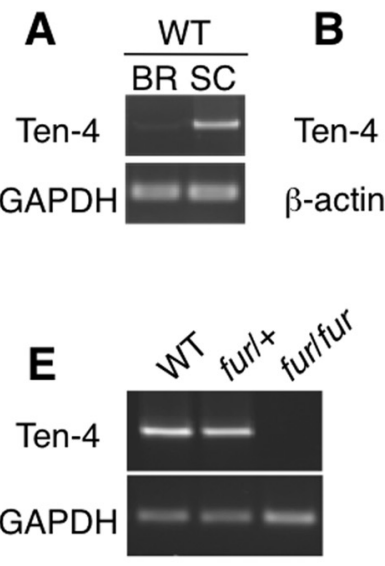

G
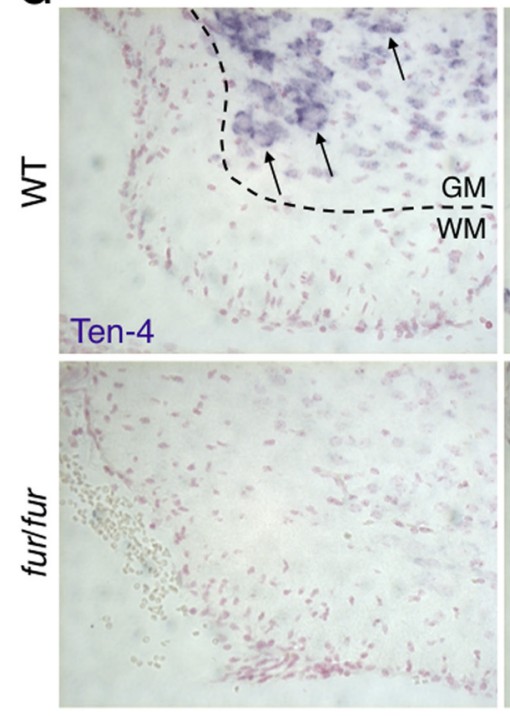

F

Ten-4

$\beta$-actin
C

$\begin{array}{llll}\frac{\text { WT: SC }}{\text { E18 }} & \text { P0 } & \text { P3 } & \text { P6 P30 P150 }\end{array}$

D

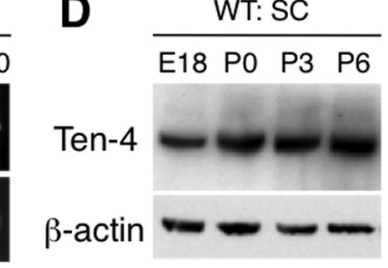

GAPDH
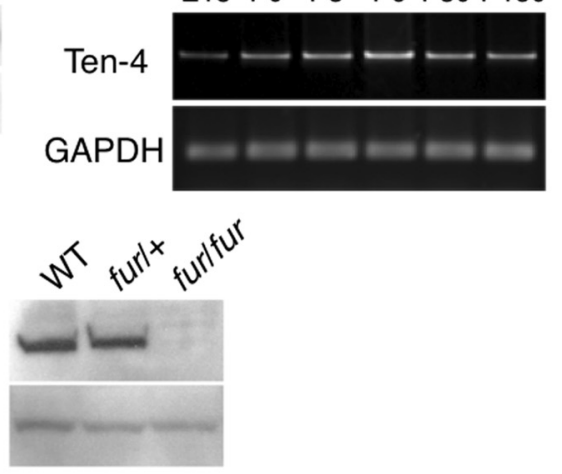

P6
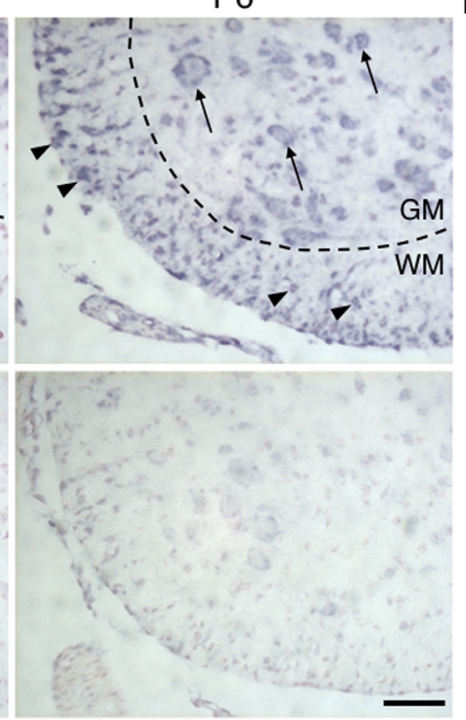

H

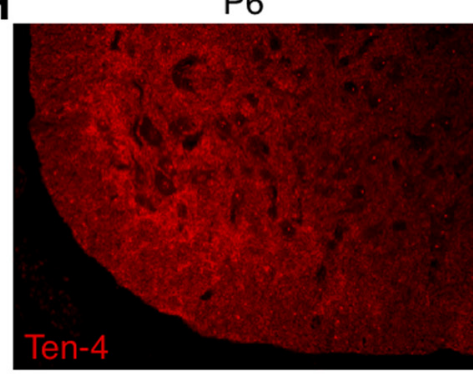

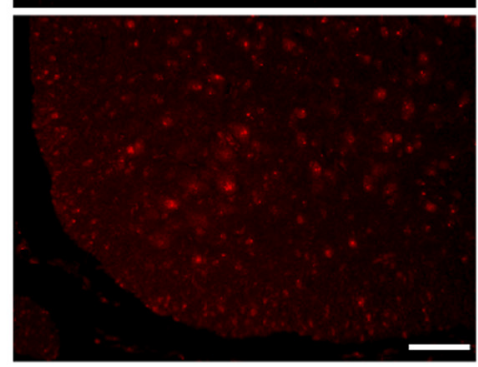

Figure 7. $\quad \boldsymbol{A}, \boldsymbol{B}$, Deficiency in Ten-4 expression in fur/fur mice. RT-PCR $(\boldsymbol{A})$ and Western blotting $(\boldsymbol{B})$ of Ten- 4 in both the brain and spinal cord of WT mice at P6. In the WT mice, Ten-4 mRNA and protein expression in the spinal cord was higher than in the brain. The expression of GAPDH and $\beta$-actin was used as the control in RT-PCR and Western blotting, respectively. BR, Brain; SC, spinal cord. $C, \boldsymbol{D}, \mathrm{RT}-\mathrm{PCR}(\boldsymbol{C})$ and Western blotting $(\boldsymbol{D})$ of Ten-4 in the WT spinal cord at various stages. The highest expression of Ten- 4 was observed at P6. The expression of GAPDH and $\beta$-actin was used as the control in RT-PCR and Western blotting, respectively. $\boldsymbol{E}, \boldsymbol{F}, \mathrm{RT}-\mathrm{PCR}(\boldsymbol{E})$ and Western blotting $(\boldsymbol{F})$ of Ten-4 in the spinal cords of the WT, fur/ + , and fur/fur mice at P8. Ten-4 expression was absent in the fur/fur mice. The expression of GAPDH and $\beta$-actin was used as the control in RT-PCR and Western blotting, respectively. G, In situ hybridization of Ten-4 in the spinal cords of WT and fur/fur mice at $\mathrm{P} 0$ and $\mathrm{P} 6$. Neurons and oligodendrocytes expressed Ten- 4 at P6, whereas in P0, Ten-4 expression was observed in neurons but not in oligodendrocytes. Spinal cord sections of fur/fur mice were used. Arrows, Ten-4-expressing neurons; arrowheads, Ten-4-expressing oligodendrocytes; GM, gray matter; WM, white matter. Scale bar, $100 \mu \mathrm{m}$. $\boldsymbol{H}$, Immunostaining of Ten-4 in the spinal cords of WT and fur/fur mice at P6. Punctuated immunostaining of Ten-4 was observed in the gray and white matter at P6. Spinal cord sections from fur/fur mice were used. Scale bar, $100 \mu \mathrm{m}$.

0.006), whereas TUNEL and GalC double-positive cells were not found (data not shown). These data indicate that the fur/fur mutation did not affect survival of progenitors and oligodendrocytes during in vitro differentiation. This was in contrast to the in vivo observation that the TUNEL-positive cells were increased in the white matter of the fur/fur spinal cord (Fig. $4 E$ ). In vivo, axon interactions and various survival factors, such as axonal factors, are required for oligodendrocyte survival (Trapp et al., 1997). fur/fur oligodendrocytes may have died in vivo through apoptosis, because they were probably unable to interact with axons properly and/or receive survival signals.

\section{Absence of Ten-4 expression in fur/fur mice caused by the transgene insertion into the Ten- 4 gene}

Because the tremor phenotype in fur/fur mice is likely caused by a defect in a gene whose function is disrupted by the transgene insertion, we attempted to identify the transgene insertion site. FISH analysis showed only one transgene insertion site in the genome and its location on chromosome 7 (Fig. 6A). Screening of a bacterial artificial chromosome genomic library prepared from the fur/fur mice identified the transgene insertion into intron 5 of the Ten-4 (alternative name Odz4) gene, located on chromosome 7 (Fig. 6B, C). Analyses of Southern blotting, PCR, and sequencing revealed that the $3 \mathrm{~kb}$ flanking region was duplicated in the $5^{\prime}$ and $3^{\prime}$ sites where the transgene was inserted (Fig. $6 C$, gray lines, $D$ ). This duplication likely occurred when the transgene was integrated into the Ten-4 gene.

Ten-4 is a highly expressed CNS transmembrane protein whose function is as yet unknown (Kenzelmann-Broz et al., 2010). Ten-4 mRNA and protein were expressed in the brain and were expressed strongly in the spinal cord of WT mice (Fig. $7 A, B)$. Ten- 4 mRNA was also weakly detected in the kidney, the lung, and the spleen of WT mice (data not shown). In the WT spinal cord, higher expression of Ten-4 was observed during the early postnatal stages (Fig. $7 C, D$ ), when the defects in oligodendrocyte differentiation, including the reduced expression of my- 
A
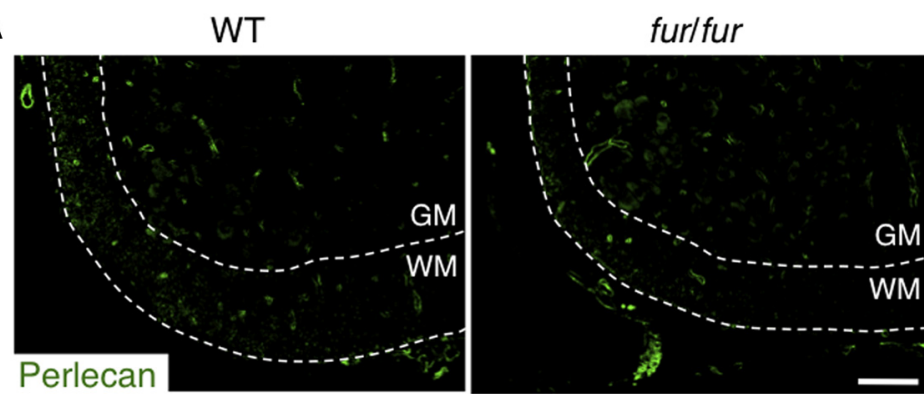

B

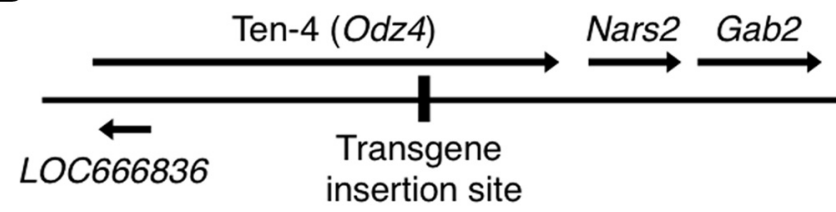

C

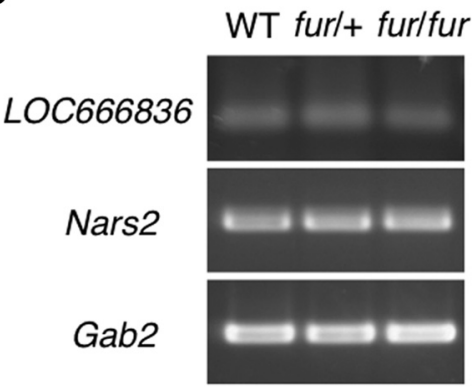

Figure 8. No effect of the transgene insertion on the expression of transgene and neighboring genes of the Ten-4 gene. $\boldsymbol{A}$ Immunostaining of perlecan in the spinal cords of the WT and fur/fur mice at P7. Immunostaining of perlecan in the basement membranes surrounding capillaries was detected in WT and fur/fur spinal cords. No significant difference in the immunostaining of perlecan was observed between the WT and fur/fur spinal cords. GM, Gray matter; WM, white matter. Scale bar, $100 \mu \mathrm{m}$. $\boldsymbol{B}$, Locations of the transgene insertion site, Ten-4 gene, and neighboring genes, LOC666836, Nars2, and Gab2. C, RT-PCR of LOC666836, Nars2, and Gab2 in the spinal cords of the WT, fur/+, and fur/fur mice. There was no significant difference in the mRNA expression levels of LOC666836, Nars2, or Gab2 among the WT, fur/+, and fur/fur mice.

elin proteins, were initiated in the fur/fur spinal cord (Figs. 3, 4). In situ hybridization revealed that Ten- 4 mRNA was expressed in neurons (Fig. 7G, arrows) and oligodendrocytes (Fig. 7G, arrowheads) of the WT spinal cord at P6, whereas only neurons expressed Ten-4 at P0. This indicates that Ten-4 expression in oligodendrocytes was upregulated during oligodendrocyte differentiation. In contrast, the fur/fur spinal cord showed no detectable Ten-4 mRNA signals in neurons or oligodendrocytes at either P0 or P6 (Fig. 7G). The expression of Ten-4 mRNA and protein was also absent in the fur/fur spinal cord in the RT-PCR and Western blot analyses (Fig. 7E,F). Heterozygous fur/ + mice, which theoretically have $50 \%$ Ten- 4 expression level of WT mice, did not exhibit tremors. We found that the expression levels of Ten-4 in the spinal cord of furl + mice were similar to that in WT mice (Fig. $7 E, F$ ). This suggests that the Ten- 4 expression in fur ++ mice is compensated by an upregulation from the WT allele in fur/ + mice. Immunostaining for Ten- 4 showed punctate localization in both the white and gray matter of the P6 WT spinal cord, whereas its signals were substantially reduced in the fur/fur spinal cord (Fig. $7 H$ ). The expression of Ten-4 was not detectable in other tissues of fur/fur mice, such as the brain, kidney, lung, and spleen (data not shown). This suggests that the transgene insertion abolished the expression of Ten-4 in fur/fur mice.

To confirm that the defect in Ten-4 expression was associated with the phenotypes in fur/fur mice, we examined perlecan expression in fur/fur mice, because the perlecan transgene under the cartilage-specific promoter was inserted into the Ten-4 gene in furl fur mice. Perlecan was expressed primarily in the basement membranes of capillaries in the spinal cords and brains of both WT and fur/fur mice, with no substantial differences in the expression levels (Fig. $8 \mathrm{~A}$ and data not shown). This indicates that the perlecan transgene under the cartilage-specific promoter was not expressed in the CNS of fur/fur mice. Furthermore, we analyzed mRNA expression of Ten-4 neighboring genes, LOC666836, Nars2, and Gab2, in the spinal cords of WT, furl +, and furl fur mice and found no substantial difference in the expression level of these genes (Fig. $8 B, C$ ). Thus, the expression of the perlecan transgene and the neighboring genes did not influence the CNS defects and the tremors in fur/fur mice. These data suggest that the deficiency of Ten-4 was likely responsible for the defects and the tremor phenotype in furl fur mice.

\section{Inhibition of differentiation and cell process formation in the OPC line CG-4 by knockdown of Ten-4 expression}

We further analyzed whether Ten-4 is required for oligodendrocyte differentiation using the OPC line CG-4, which can differentiate into oligodendrocyte-like cells with increase of myelin protein expression in the presence of the $\mathrm{T}_{3}$ thyroid hormone (Louis et al., 1992). During differentiation, CG-4 cells increased the number and area of cellular processes, and the processes formed multiple branches (Fig. 9A). In undifferentiated CG-4 cells, Ten- 4 mRNA was expressed at low levels, and the Ten- 4 protein was localized in cell body regions (Fig. 9B, C). Ten-4 expression was increased during differentiation, accompanied by the expression of oligodendrocyte markers CNP, MAG, and PLP (Fig. 9B and data not shown). However, the expression of PDGFR- $\alpha$, an OPC marker, was decreased (Fig. 9B). Immunostaining revealed that the Ten-4 protein was found in puncta throughout the cellular processes, as well as in the nuclei (Fig. 9C). The Ten-4 expression pattern during CG-4 differentiation was consistent with the in vivo results (Fig. 7). We next established Ten- 4 knockdown CG-4 cells by stable transfection with shRNA for Ten-4 (shTen-4) and examined cell differentiation. Quantitative RTPCR showed that, 3 days after the induction of differentiation, Ten-4 mRNA expression in CG-4 cells transfected with shTen-4 (shTen- 4 cells) was reduced to $59.5 \pm 4.3 \%$ of that in control shRNA (shCont)-transfected CG-4 cells (shCont cells) (Fig. 9D). We found that the mRNA expression levels of CNP, MAG, and PLP were also significantly decreased in shTen-4 cells, whereas the expression level of PDGFR- $\alpha$ mRNA did not change (Fig. 9D). The knockdown of Ten- 4 by another shRNA construct with different sequences yielded similar results (data not shown). In addition, the total cell area and the number of branching points of cell processes were reduced in shTen- 4 cells compared with those in differentiating shCont cells (Fig. 9E). These results 
A

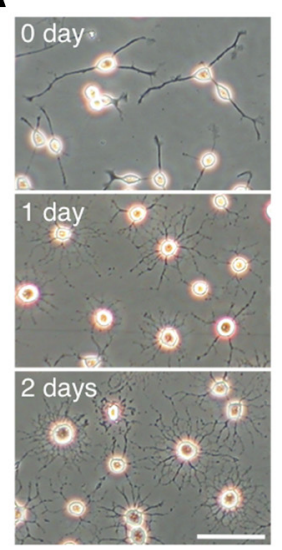

B
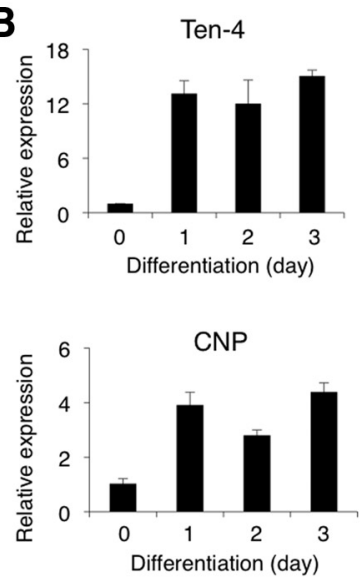
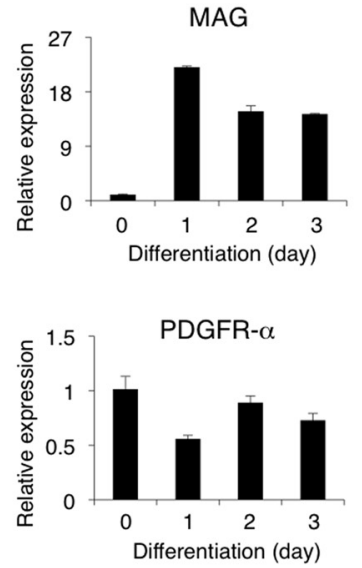

C

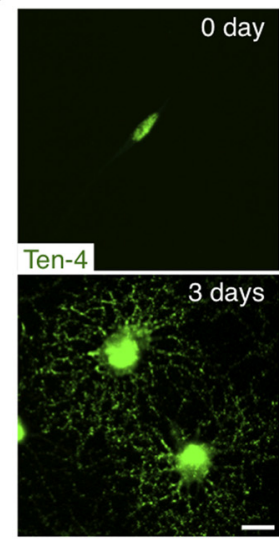

D

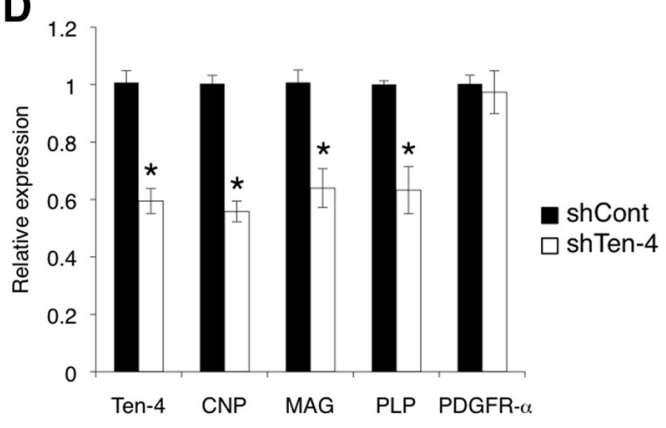

E

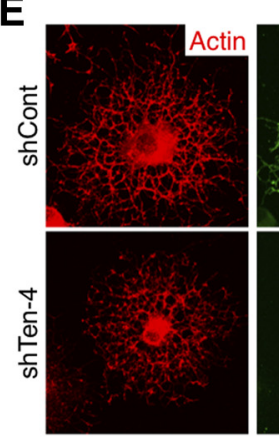

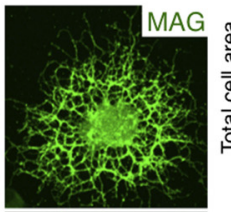

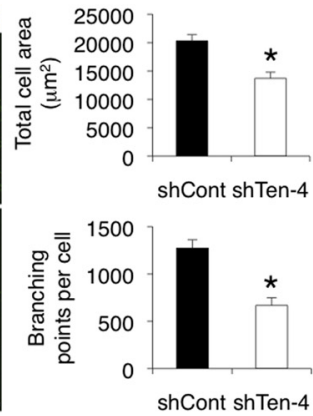

Figure 9. Expression of Ten-4 in the OPC line (G-4 and inhibition of (G-4 differentiation by Ten-4 knockdown. A, Cell morphology of CG-4 cells during differentiation induced with $\mathrm{T}_{3}$. CG-4 cells radially formed highly branched cell processes after the induction of differentiation. Scale bar, $100 \mu \mathrm{m}$. B, Quantitative RT-PCR of Ten-4, MAG, CNP, and PDGFR- $\alpha$ in CG-4 cells during differentiation. The mRNA expression of Ten- 4 was increased after induction of differentiation, similar to that of MAG and CNP, whereas PDGFR- $\alpha$ mRNA expression was slightly decreased. The mRNA expression of each gene was normalized using GAPDH mRNA expression. The normalized expression of each gene at $0 \mathrm{~h}$ was set as 1.0. Error bars indicate SEM. C, Immunostaining of Ten-4 in CG-4 cells during differentiation. The punctuated immunostaining of Ten-4 in cell processes increased during (G-4 differentiation. Scale bar, $5 \mu \mathrm{m}$. D, Quantitative RT-PCR of Ten-4, CNP, MAG, PLP, and PDGFR- $\alpha$ in CG-4 cells transfected with the control (shCont) or Ten-4 (shTen-4) shRNA vector, $3 \mathrm{~d}$ after induction of differentiation. Ten- 4 mRNA expression in shTen- 4 cells was $59.5 \pm 4.3 \%$ of Ten- 4 mRNA expression in shCont cells. The mRNA expression of CNP, MAG, and PLP was significantly reduced in shTen-4 cells. No difference in PDGFR- $\alpha$ mRNA expression was observed. The mRNA expression of each gene was normalized using GAPDH mRNA expression. The normalized expression of each gene in shCont cells was set as 1.0. Error bars indicate SEM; ${ }^{*} p<0.002$. E, Morphology of shCont and shTen-4 cells $3 \mathrm{~d}$ after induction of differentiation. In shTen-4 cells, there was a smaller total cell area and fewer branching points than in shCont cells. MAG and actin staining were used to observe differentiation and morphology, respectively. Scale bar, $5 \mu \mathrm{m}$. Error bars indicate SEM; ${ }^{*} p<0.05$.

indicate that Ten- 4 was required for the differentiation and cell process formation of CG-4 cells. These findings in the CG-4 cell cultures agreed with those in the fur/fur spinal cord and in the primary culture (Figs. 4, 5).

\section{Regulation of FAK activity by Ten-4}

To address the molecular mechanism of the Ten- 4 function in process formation of oligodendrocytes and myelination in the CNS, we examined the activity of FAK in the spinal cord of fur/fur mice and in differentiating CG-4 cells, because FAK is a key molecule of process outgrowth and CNS myelination, particularly myelination of small-diameter axons (Hoshina et al., 2007; Câmara et al., 2009). We found that phosphorylation of FAK was reduced in the fur/fur spinal cord, in the early postnatal stages $(75.7 \pm 0.5 \%)$ (Fig. 10A). During WT CG-4 cell differentiation, phosphorylation of FAK was increased (data not shown), as reported previously (Hoshina et al., 2007). In shTen-4 cells, the FAK phosphorylation level was significantly reduced (50.4 \pm $5.1 \%)$ compared with that in shCont cells, after induction of differentiation (Fig. $10 \mathrm{~B}$ ). These results suggest that Ten-4 was required for the activation of FAK during the differentiation and process formation of oligodendrocytes and myelination in vivo and in vitro.
We further confirmed the Ten-4-mediated FAK activation by transfection of CA-FAK and DN-FAK into Ten-4 knockdown CG-4 cells by shTen-4 (Fig. 10C-E). The knockdown of Ten-4 and overexpression of FAK were confirmed by quantitative RTPCR (Fig. 10C). We examined mRNA expression of PLP and PDGFR- $\alpha$, marker genes for oligodendrocytes and progenitor cells, respectively. The mRNA expression level of PLP in the shTen-4- and CA-FAK-cotransfected cells was significantly increased compared with the shTen- 4 single transfection, shTen- 4 and mock cotransfection, and shTen- 4 and DN-FAK cotransfection, although the PLP expression level with these four transfections was lower than it was with the shCont single transfection (Fig. 10C). There were no differences in the PDGFR- $\alpha$ mRNA expression levels (Fig. 10C). In addition, we analyzed cell morphology of these cells. The shTen-4 plasmid and the FAK constructs express GFP and IL2R tags, respectively. Therefore, the morphology of GFP and IL2R dual-positive cells was analyzed. The cellular process formation of the shTen-4- and CA-FAKcotransfected cells, including length and branching of the processes, was similar to the shCont-transfected cells, whereas no obvious difference was observed between the shTen-4-transfected, shTen-4and mock-cotransfected, and shTen-4- and DN-FAK-cotransfected cells (Fig. 10D,E). These data indicate that CA-FAK rescued the 

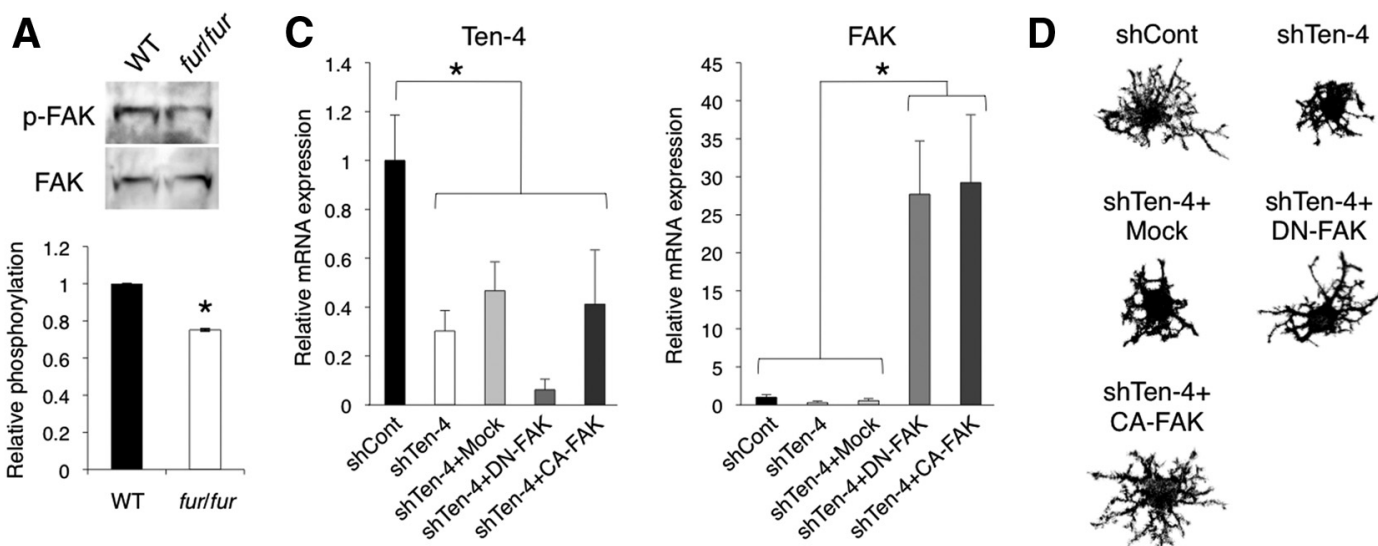

shTen-4+

Mock

DN-FAK
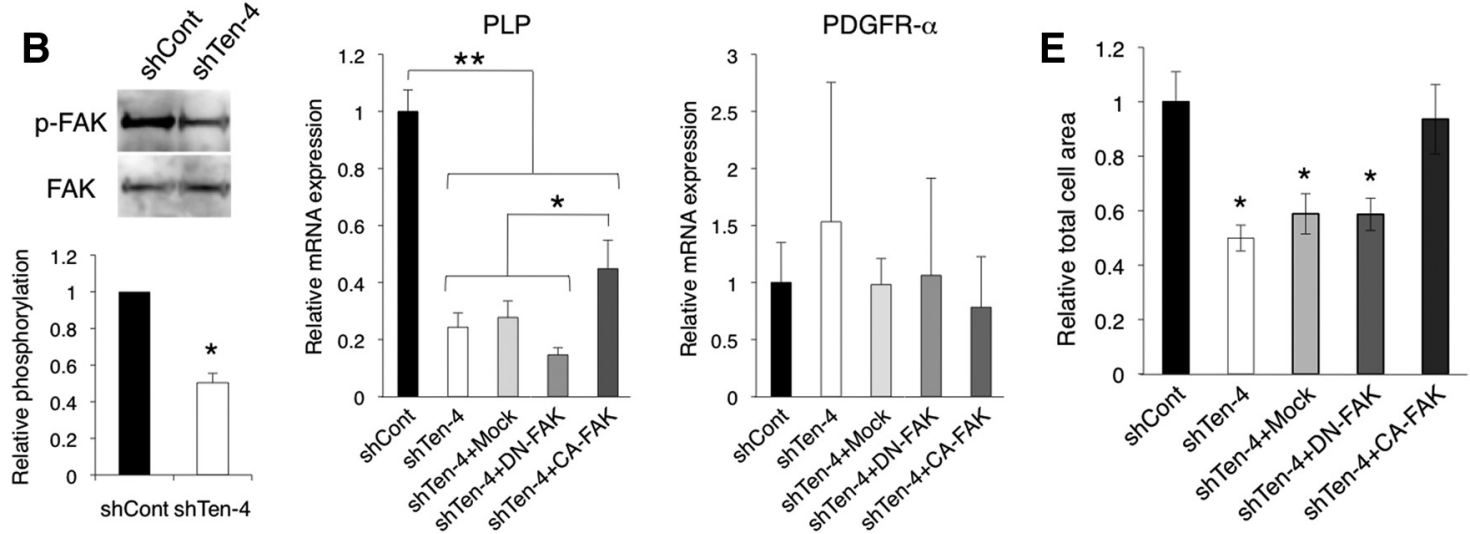

Figure 10. Reduced activation of FAK in Ten-4 knockdown CG-4 cells. $A, B$, Western blotting of p-FAK (Tyr397) and FAK in the P7-P9 spinal cords of WT and fur/fur mice ( $A$ ) and in CG-4 cells transfected with the control (shCont) or Ten-4 (shTen-4) shRNA vector after induction of differentiation (B). The phosphorylation level of FAK was reduced in the fur/fur spinal cord and in shTen-4 cells. The intensity of the phospho-FAK bands was normalized using the intensity of the total FAK bands. For quantification of the spinal cord data, three different littermates were used. Error bars indicate SEM; ${ }^{*} p<0.01$. C, Quantitative RT-PCR for Ten-4, FAK, PLP, and PDGFR- $\alpha$ genes. RNA was prepared from CG-4 cells transfected with various constructs $1 \mathrm{~d}$ after induction of differentiation. shTen-4 reduced Ten-4 expression. FAK mRNA levels were increased in shTen-4 cells by transfection with either CA-FAK or DN-FAK. Overexpression of CA-FAK, but not DN-FAK, increased PLP expression levels in shTen-4 cells. No difference in PDGFR- $\alpha$ mRNA expression levels was observed. The mRNA expression of each gene was normalized using GAPDH mRNA expression. The normalized expression of each gene in shCont cells was set as 1.0. Error bars indicate SEM; ${ }^{*} p<0.05 ;{ }^{* *} p<0.003$. D, Representative cell process formation shown by actin staining. Morphology of cells positive for GFP (shCont- or shTen-4-transfected (G-4 cells) and double-positive GFP/IL2R (shTen-4 + Mock-, shTen-4 + DN-FAK-, and Ten-4 + CA-FAK-cotransfected (G-4 cells) was analyzed 1 d after induction of differentiation. E, Quantification of the relative total cell area of these (G-4 cells. The CA-FAK overexpression restored the decreased cell area by Ten-4 knockdown. The normalized total cell area in the shCont cells was set as 1.0. Error bars indicate SEM; ${ }^{*} p<0.005$.

defects of cell process formation and increased oligodendrocyte differentiation in the Ten-4 knockdown cells. Together, our data showed that FAK is a critical downstream molecule of Ten-4 signaling in oligodendrocyte differentiation, although there may be other pathways that are activated downstream of Ten-4 for the oligodendrocyte gene expression.

\section{Discussion}

In this report, we have identified and characterized a mouse model, furue, with the gene insertion mutation in the Ten-4 gene. The fur/fur mice were deficient in Ten-4 expression and developed tremors and hypomyelination in the CNS. Myelination of small-diameter axons in particular was dramatically reduced in fur/fur mice. In the fur/fur spinal cord and primary culture, OPCs were formed, but additional differentiation to oligodendrocytes was inhibited. These results are consistent with the Ten- 4 expression pattern in which Ten-4 expression is induced during differentiation and myelination, and its expression level is low in OPCs, as shown in Figure $7 G$ as well as in the previous report using the microarray analysis of oligodendrocytes from neonatal mice (Cahoy et al., 2008). The differentiation defect results in a lower production of myelin proteins and reduced cell process formation. Thus, Ten-4 is a critical regulator of oligodendrocyte differentiation and CNS myelination.
In fur/fur mice, the tremor phenotype was observed as a result of the hypomyelination in the CNS, such as in the spinal cord and the corpus callosum, but not in the PNS sciatic nerve (Figs. 1, 2). Several mutant tremor mice accompanying with CNS hypomyelination have been characterized previously. For instance, jimpy mice and the conditional knock-out mice of myelin gene regulatory factor (MRF) have mutations in genes of myelin component protein PLP and the putative transcription factor MRF, respectively, and develop tremors (Vela et al., 1998; Emery et al., 2009). In these mutant tremor mice, oligodendrocytes are not produced or disappear because of defects in cell differentiation or survival, respectively, causing hypomyelination in the CNS. Similarly, in fur/fur mice, the differentiation of oligodendrocytes was inhibited (Figs. 4, 5), which led to the hypomyelination in the CNS. The number of TUNEL-positive cells was also increased in the white matter of the fur/fur spinal cord (Fig. $4 E$ ). However, there was no increase in TUNEL-positive cells in the primary culture (Fig. $5 F, G)$. The increased TUNEL-positive cells in vivo may be caused by a secondary effect of differentiation inhibition and cell process formation in fur/fur oligodendrocytes. Apoptosis is usually induced in oligodendrocytes as a result of failure of differentiation and/or myelination (Trapp et al., 1997; Emery et al., 2009). 
Interestingly, severe hypomyelination was observed in the smalldiameter axons in furlfur mice, whereas the large-diameter axons were myelinated (Figs. $1 \mathrm{~J}, 2 \mathrm{D}$ ). In other mutant tremor mice, such as jimpy mice and the MRF conditional knock-out mice, both small- and large-diameter axons are not myelinated (Vela et al., 1998; Emery et al., 2009). In that sense, the mechanism of the CNS hypomyelination and the tremors in fur/fur mice is unique. Recently, the role of integrin $\beta 1$ and FAK in CNS myelination has been identified. Exogenous expression of the DN form of integrin $\beta 1$ in oligodendrocytes and the oligodendrocyte-specific deletion of FAK cause defects in CNS myelination of small-diameter axons in mice that are similar to those seen in fur/fur mice, whereas in these mutant mice, the defects are mild and no neurological phenotype, such as tremors, is observed (Câmara et al., 2009). Two possible explanations for the small-diameter axon-specific phenotype have been proposed (Câmara et al., 2009). First, there is an axonal signal proportional to diameter, and a minimal amount of the axonal signals is required for myelination by oligodendrocytes through integrin $\beta 1-F A K$ signaling. In the mutants of integrin $\beta 1$ and FAK, oligodendrocytes fail to obtain the axonal signals from small-diameter axons because the amount of axonal factors on small-diameter axons is under the minimal amount, whereas the amount on large-diameter axons is more. In fur/fur mice, oligodendrocytes may be unable to receive the signal from small-diameter axons. Second, myelination of smalldiameter axons requires well-organized and branched cellular processes of oligodendrocytes. There are four subtypes of oligodendrocytes (types I-IV) in the CNS (Butt and Berry, 2000): types I and II oligodendrocytes form well-organized and branched cell processes and myelinate numerous small-diameter axons, whereas types III and IV oligodendrocytes form myelin on a small number of large-diameter axons. We found that cellular process formation was inhibited in Ten-4-deficient oligodendrocytes and CG-4 cells (Figs. 5, 9, 10). Similar defects in cellular process formation are shown in FAK- or integrin $\beta 1$-deficient oligodendrocytes and FAK knockdown CG-4 cells (Hoshina et al., 2007; Barros et al., 2009; Lafrenaye and Fuss, 2010). The defects in branched cellular processes of Ten-4-deficient oligodendrocytes may cause hypomyelination of small-diameter axons more selectively than large-diameter axons. We showed that activated FAK was able to rescue cellular process formation of Ten-4 knockdown CG-4 cells (Fig. 10), suggesting that Ten-4 regulates integrin $\beta 1-\mathrm{FAK}$ signaling and plays a critical role in the myelination of small-diameter axons. The phenotype and smalldiameter axon hypomyelination in the CNS of fur/fur mice were more profound than those in the integrin $\beta 1$ and FAK mutant mice. The more severe phenotype of fur/fur mice suggests that Ten-4 functions through multiple signaling pathways in addition to Ten-4/integrin $\beta 1 / \mathrm{FAK}$ signaling.

Ten-4 was expressed not only in oligodendrocytes but also in neurons of the WT spinal cord during early postnatal stages (Fig. $7 G$ ), although no obvious defect was observed in the neurons of the fur/fur spinal cord (Fig. 3). In the cortex of the brain, Ten-4 expression increases in layer $\mathrm{V}$ neurons, whose small-diameter axons project to the spinal cord and form the corticospinal tract between P2 and P7 (Li et al., 2006). Our data showed no significant difference in immunostaining of neurofilaments between the WT and fur/fur corticospinal tracts at P6 (data not shown) or of the lateral funiculus (Fig. $3 A, B$ ). It is also possible that Ten-4 may act as an axonal factor or as both the axonal and oligodendroglial factors that are crucial for the myelination of smalldiameter axons.
The tremor phenotype in fur/fur mice was predominantly observed in the hindlimbs (see Notes). In the dorsal column of the fur/fur spinal cord, severe defects in myelin formation were found in the corticospinal tract and fasciculus gracilis (Fig. 1E,F). The corticospinal tract is one of the major motor tracts and consists of small-diameter axons. The fasciculus gracilis is the region from which the small-diameter axons of the sensory neurons of the lower body ascend. Therefore, the defects in myelination of small-diameter axons in the corticospinal tract and the fasciculus gracilis are likely what cause the hindlimb-dominant tremors in the fur/fur mice. In patients with multiple sclerosis, a dysmyelinating disease, small-diameter axons are selectively damaged in the corticospinal and sensory tracts of the spinal cord (DeLuca et al., 2004). Ten-4 may play an important role in multiple sclerosis.

There are four isoforms (teneurin-1 to -4) among the teneurin family in vertebrates. All teneurin members are expressed in neurons (Tucker and Chiquet-Ehrismann, 2006), whereas only Ten-4 is expressed in the white matter of the cerebellum of adult mice, in which oligodendrocytes, but not neurons, are present in abundance (Zhou et al., 2003). Therefore, Ten-4 is the only teneurin member expressed in oligodendrocytes, whereas in neurons, the other teneurin members may compensate for the Ten- 4 function. Indeed, an increase in teneurin-1 and teneurin-3 mRNA expression was observed in the fur/fur spinal cord (data not shown). It is also interesting to note that only one teneurin gene exists in invertebrates, whose axons are unmyelinated. It is tempting to speculate that, during evolution, vertebrates may have produced a diversity of teneurin genes and acquired the Ten-4 gene to form myelin in the CNS.

In summary, our in vivo and in vitro results provide evidence that Ten- 4 is a novel regulator of the differentiation and process formation of oligodendrocytes and CNS myelination. The fur/fur mutant mouse model will facilitate a better understanding of oligodendrocyte biology, as well as the development of diagnostic and therapeutic reagents for dysmyelinating diseases, such as multiple sclerosis.

\section{Notes}

Supplemental material for this article is available at http://www.youtube. $\mathrm{com} /$ watch? $\mathrm{v}=\mathrm{bcmcjLuB}$ bs). Movie 1 shows tremors of fur/fur mice at 6 weeks after birth. The onset of the tremor phenotype of fur/fur mice started $\sim 4$ weeks after birth. The severe tremors in the hindlimbs were observed when furlfur mice were walking but not when they were resting. This material has not been peer reviewed.

\section{References}

Barros CS, Nguyen T, Spencer KS, Nishiyama A, Colognato H, Müller U (2009) Betal integrins are required for normal CNS myelination and promote AKT-dependent myelin outgrowth. Development 136: 2717-2724.

Baumann N, Pham-Dinh D (2001) Biology of oligodendrocyte and myelin in the mammalian central nervous system. Physiol Rev 81:871-927.

Butt AM, Berry M (2000) Oligodendrocytes and the control of myelination in vivo: new insights from the rat anterior medullary velum. J Neurosci Res 59:477-488.

Cahoy JD, Emery B, Kaushal A, Foo LC, Zamanian JL, Christopherson KS, Xing Y, Lubischer JL, Krieg PA, Krupenko SA, Thompson WJ, Barres BA (2008) A transcriptome database for astrocytes, neurons, and oligodendrocytes: a new resource for understanding brain development and function. J Neurosci 28:264-278.

Câmara J, Wang Z, Nunes-Fonseca C, Friedman HC, Grove M, Sherman DL, Komiyama NH, Grant SG, Brophy PJ, Peterson A, ffrench-Constant C (2009) Integrin-mediated axoglial interactions initiate myelination in the central nervous system. J Cell Biol 185:699-712.

Chomiak T, Hu B (2009) What is the optimal value of the g-ratio for myelinated fibers in the rat CNS? A theoretical approach. PLoS One 4:e7754. 
DeLuca GC, Ebers GC, Esiri MM (2004) Axonal loss in multiple sclerosis: a pathological survey of the corticospinal and sensory tracts. Brain 127:1009-1018.

Emery B, Agalliu D, Cahoy JD, Watkins TA, Dugas JC, Mulinyawe SB, Ibrahim A, Ligon KL, Rowitch DH, Barres BA (2009) Myelin gene regulatory factor is a critical transcriptional regulator required for CNS myelination. Cell 138:172-185.

Forrest AD, Beggs HE, Reichardt LF, Dupree JL, Colello RJ, Fuss B (2009) Focal adhesion kinase (FAK): a regulator of CNS myelination. J Neurosci Res 87:3456-3464.

Griffiths IR (1996) Myelin mutants: model systems for the study of normal and abnormal myelination. Bioessays 18:789-797.

Horiuchi M, Lindsten T, Pleasure D, Itoh T (2010) Differing in vitro survival dependency of mouse and rat NG2+ oligodendroglial progenitor cells. J Neurosci Res 88:957-970.

Hoshina N, Tezuka T, Yokoyama K, Kozuka-Hata H, Oyama M, Yamamoto $\mathrm{T}$ (2007) Focal adhesion kinase regulates laminin-induced oligodendroglial process outgrowth. Genes Cells 12:1245-1254.

Katz BZ, Miyamoto S, Teramoto H, Zohar M, Krylov D, Vinson C, Gutkind JS, Yamada KM (2002) Direct transmembrane clustering and cytoplasmic dimerization of focal adhesion kinase initiates its tyrosine phosphorylation. Biochim Biophys Acta 1592:141-152.

Kenzelmann-Broz D, Tucker RP, Leachman NT, Chiquet-Ehrismann R (2010) The expression of teneurin-4 in the avian embryo: potential roles in patterning of the limb and nervous system. Int J Dev Biol 54:1509-1516.

Lafrenaye AD, Fuss B (2010) Focal adhesion kinase can play unique and opposing roles in regulating the morphology of differentiating oligodendrocytes. J Neurochem 115:269-282.

Li H, Bishop KM, O'Leary DD (2006) Potential target genes of EMX2 include Odz/Ten-M and other gene families with implications for cortical patterning. Mol Cell Neurosci 33:136-149.

Lossie AC, Nakamura H, Thomas SE, Justice MJ (2005) Mutation of $17 \mathrm{Rn} 3$ shows that Odz4 is required for mouse gastrulation. Genetics 169:285-299.

Louis JC, Magal E, Muir D, Manthorpe M, Varon S (1992) CG-4, a new bipotential glial cell line from rat brain, is capable of differentiating in vitro into either mature oligodendrocytes or type-2 astrocytes. J Neurosci Res 31:193-204.
Matsui S, Sait S, Jones CA, Nowak N, Gross KW (2002) Rapid localization of transgenes in mouse chromosomes with a combined Spectral Karyotyping/FISH technique. Mamm Genome 13:680-685.

Noonan DM, Fulle A, Valente P, Cai S, Horigan E, Sasaki M, Yamada Y, Hassell JR (1991) The complete sequence of perlecan, a basement membrane heparan sulfate proteoglycan, reveals extensive similarity with laminin A chain, low density lipoprotein-receptor, and the neural cell adhesion molecule. J Biol Chem 266:22939-22947.

Rajasekharan S, Baker KA, Horn KE, Jarjour AA, Antel JP, Kennedy TE (2009) Netrin 1 and Dcc regulate oligodendrocyte process branching and membrane extension via Fyn and RhoA. Development 136:415-426.

Sklar P, Ripke S, Scott LJ, Andreassen OA, Cichon S, Craddock N, Edenberg HJ, Nurnberger JI Jr, Rietschel M, Blackwood D, Corvin A, Flickinger M, Guan W, Mattingsdal M, McQuillin A, Kwan P, Wienker TF, Daly M, Dudbridge F, Holmans PA, et al. (2011) Large-scale genome-wide association analysis of bipolar disorder identifies a new susceptibility locus near ODZ4. Nat Genet 43:977-983.

Trapp BD, Nishiyama A, Cheng D, Macklin W (1997) Differentiation and death of premyelinating oligodendrocytes in developing rodent brain. J Cell Biol 137:459-468.

Tsumaki N, Tanaka K, Arikawa-Hirasawa E, Nakase T, Kimura T, Thomas JT, Ochi T, Luyten FP, Yamada Y (1999) Role of CDMP-1 in skeletal morphogenesis: promotion of mesenchymal cell recruitment and chondrocyte differentiation. J Cell Biol 144:161-173.

Tucker RP, Chiquet-Ehrismann R (2006) Teneurins: a conserved family of transmembrane proteins involved in intercellular signaling during development. Dev Biol 290:237-245.

Vela JM, González B, Castellano B (1998) Understanding glial abnormalities associated with myelin deficiency in the jimpy mutant mouse. Brain Res Brain Res Rev 26:29-42.

Wang XZ, Kuroda M, Sok J, Batchvarova N, Kimmel R, Chung P, Zinszner H, Ron D (1998) Identification of novel stress-induced genes downstream of chop. ЕMBO J 17:3619-3630.

Zhou XH, Brandau O, Feng K, Oohashi T, Ninomiya Y, Rauch U, Fässler R (2003) The murine Ten-m/Odz genes show distinct but overlapping expression patterns during development and in adult brain. Gene Expr Patterns 3:397-405. 